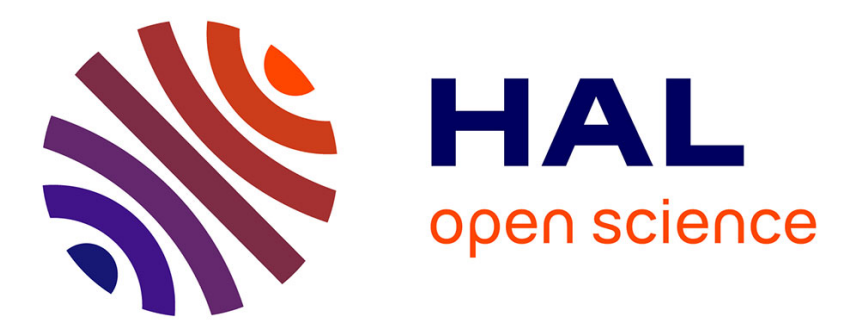

\title{
A Person-Centred Perspective on Social Support in the Workplace
}

\author{
Gaëtane Caesens, Nicolas Gillet, Alexandre J.S. Morin, Simon A. Houle, \\ Florence Stinglhamber
}

\section{> To cite this version:}

Gaëtane Caesens, Nicolas Gillet, Alexandre J.S. Morin, Simon A. Houle, Florence Stinglhamber. A Person-Centred Perspective on Social Support in the Workplace. Applied Psychology, 2020, 69 (3), pp.686 - 714. 10.1111/apps.12196 . hal-03129517

\section{HAL Id: hal-03129517 https://hal.science/hal-03129517}

Submitted on 2 Feb 2021

HAL is a multi-disciplinary open access archive for the deposit and dissemination of scientific research documents, whether they are published or not. The documents may come from teaching and research institutions in France or abroad, or from public or private research centers.
L'archive ouverte pluridisciplinaire HAL, est destinée au dépôt et à la diffusion de documents scientifiques de niveau recherche, publiés ou non, émanant des établissements d'enseignement et de recherche français ou étrangers, des laboratoires publics ou privés. 
Running Head: Workplace Support Profiles

\title{
A Person-Centered Perspective on Social Support in the Workplace
}

\author{
Gaëtane Caesens ${ }^{1 *}$, Nicolas Gillet ${ }^{2 *}$, Alexandre J.S. Morin ${ }^{3}$, Simon A. Houle ${ }^{3}$, and Florence \\ Stinglhamber ${ }^{1}$ \\ ${ }^{1}$ Université catholique de Louvain, Belgium \\ ${ }^{2}$ Université François-Rabelais de Tours, France \\ ${ }^{3}$ Concordia University, Canada
}

\begin{abstract}
* Since the first two authors (G.C. \& N.G.) contributed equally to the preparation of this article, their order was determined at random: both should be considered first authors.

Acknowledgements: This work was supported by the "Fonds de la Recherche Scientifique - FNRS" under grant $\mathrm{n}^{\circ} \mathrm{T} .0177 .16$ awarded to the last author. This article was prepared in part while the first author (Gaëtane Caesens) was a visiting scholar at the Substantive-Methodological Synergy Research Laboratory, Department of Psychology, Concordia University (Canada).
\end{abstract}

There are no conflicts of interest to declare

Correspondence concerning this article should be addressed to Gaëtane Caesens, Université catholique de Louvain, Place Cardinal Mercier, 10, 1348 Louvain-la-Neuve, Belgium. E-mail:

gaetane.caesens@uclouvain.be.

This is the prepublication version of the following manuscript:

Caesens, G., Gillet, N., Morin, A.J.S., Houle, S.A., \& Stinglhamber, F. (In press). A person-centered perspective on social support in the workplace. Applied Psychology: An International Review. early view doi: 10.1111/apps.12196

(C) 2017. This paper is not the copy of record and may not exactly replicate the authoritative document published in Structural Equation Modeling.

\begin{abstract}
This research seeks to identify employee's profiles characterized by distinct perceptions of three sources of social support at work (i.e., organization, supervisor, and colleagues), and the extent to which these profiles generalize across two samples of workers $(N=185$ and 387). This research also investigates the associations between the profiles and a series of outcomes. Latent profile analysis revealed five identical profiles in both samples: 1- moderately supported; 2- isolated; 3- supervisor supported; 4- weakly supported; and 5- highly supported. The most desirable outcomes (job satisfaction, performance, and affective commitment) were associated with Profile 5 (highly supported), while the highest levels of emotional exhaustion were observed in Profile 2 (isolated).
\end{abstract}

Keywords: Perceived organizational support, perceived supervisor support, perceived colleagues support, latent profile analysis. 
Organizational support theory (OST; Eisenberger \& Stinglhamber, 2011) positions employees' perceptions of the extent to which their organization cares about their well-being and values their contributions (i.e., perceived organizational support-POS) as a key determinant of employees' commitment, well-being, and proactive work behaviors (Eisenberger, Huntington, Hutchison, \& Sowa, 1986; Kurtessis et al., 2017). Despite this focus on the "organization" as a key provider of social support, organizations are not monolithic entities, and need to be understood in terms of multiple constituencies whose goals and values may complement, or conflict with, one another (Morin, Morizot, Boudrias, \& Madore, 2011). Research has shown that employees maintain distinct relationships with their organization relative to those that they share with their supervisors and coworkers (Stinglhamber, Bentein, \& Vandenberghe, 2002). This multi-foci perspective has led to the extension of OST to examine the possible complementary role of POS, perceived supervisor support (PSS), and perceived colleagues support (PCS) as key drivers of desirable outcomes (e.g., Eisenberger \& Stinglhamber, 2011; Eisenberger, Stinglhamber, Vandenberghe, Sucharski, \& Rhoades, 2002).

Research has generally shown that, when considered in isolation, POS, PSS, and PCS all represent key drivers of desirable outcomes such as job satisfaction and performance (Eisenberger \& Stinglhamber, 2011; Ng \& Sorensen, 2008). However, despite their interest, these studies are limited by their failure to consider the possible combined effects of these three sources of workplace support. In particular, despite the acknowledgement that employees might benefit from different sources of social support (e.g., Eisenberger \& Stinglhamber, 2011), little is known about the configurations that characterize these combinations and their effects on employee's well-being, attitudes, and behaviors. Indeed, previous research has relied on a variable-centered approach, which assumes that all participants are drawn from a single population and results in the estimation of a single set of "average" parameters. In contrast, person-centered approaches, such as latent profile analyses (LPA), seek to identify the subpopulations (or profiles) present in the overall sample in order to identify employees sharing a similar configuration of perceived social support at work. For this reason, the person-centered approach was specifically developed to assess the role of variable combinations.

The present study adopts such a person-centered approach to: (1) identify employees' profiles characterized by distinct configurations of POS, PSS, and PCS; (2) examine the associations between these configurations and a series of work-related outcomes related to employee well-being, attitudes, and behaviors known to be associated with workplace support perceptions; and (3) assess whether these profiles generalize across two distinct samples. From a more practical standpoint, the ability to rely on person-centered solutions to guide the development of intervention strategies is conditioned on the demonstration that similar profiles can be reliably identified across a variety of samples (e.g., Meyer \& Morin, 2016). Indeed, being able to identify similar profiles across samples indicates that generic interventions strategies (e.g., designed to help employees based on their profiles) can be developed and expected to generalize to different types of workers, which is a much more parsimonious approach than having to develop strategies targeting different types of profiles for distinct types of employees.

In this study, we rely on a set of measures selected to cover a broad range of outcomes related to well-being (emotional exhaustion and job satisfaction), positive attitudes directed at the organization (affective commitment), and employees' behaviors (performance and absenteeism). The specific outcomes in each category were selected based on previously reported evidence showing that they present well-documented variable-centered associations with workplace support (e.g., Gillet, Fouquereau, Huyghebaert, \& Colombat, 2016). We also focus on the key work outcomes of job satisfaction given mounting research evidence supporting its important role in job performance (e.g., Bowling, Khazon, Meyer, \& Burrus, 2015). Similarly, employees' affective commitment plays also an important role in the work domain and numerous studies have shown that affective commitment is an important predictor of performance (e.g., Gong, Law, Chang, \& Xin, 2009). Indeed, employees who are affectively committed to their organization are likely to act in ways that are consistent with the organization's goals and expectations, and invest more effort, thus leading to higher levels performance (Yu et al., 2016). Moreover, emotional exhaustion is an important outcome to consider given its influence on employees' decisions to quit their organization (Steffens, Yang, Jetten, Haslam, \& Lipponen, 2018). Emotional exhaustion is also related to lower levels of job performance and well-being (Demerouti, Bakker, \& Leiter, 2014; Hakanen, Peeters, \& Schaufeli, 2018). Finally, absenteeism is an important outcome to consider given it carries significant costs for organizations (Schmid et al., 2017) and its significant relation with turnover intentions (Berry, Lelchook, \& Clark, 2012). 


\section{Theoretical Perspective}

OST relies on social exchange theory and the norm of reciprocity to explain the benefits of POS. Precisely, OST suggests that employees perceiving high levels of POS should be more likely to consider favorable actions from their organization as an indication that the organization is committed toward them (Kurtessis et al., 2017). In turn, these perceptions are proposed to elicit among employees a felt obligation to reciprocate by helping the organization to attain its goals through favorable work attitudes and behaviors (Eisenberger et al., 1986). Furthermore, OST suggests that POS, by helping to fulfill employees' socioemotional needs, contributes to greater levels of well-being and positive organizational attitudes (Kurtessis et al., 2017). Indeed, research has demonstrated that POS tends to increase employees' organizational commitment, performance, and job satisfaction, and to decrease their levels of absenteeism and emotional exhaustion (e.g., Kurtessis et al., 2017).

Like POS, OST proposes that PSS and PCS contribute to enhance employees' work attitudes, behaviors, and well-being (Eisenberger \& Stinglhamber, 2011). Research on PSS and PCS has generally supported this assertion by demonstrating, for instance, positive relations between PSS and PCS and employees' job satisfaction (Caesens, Stinglhamber, \& Luypaert, 2014). These three sources of social support are not proposed to be mutually exclusive but are rather seen as complementary (Eisenberger \& Stinglhamber, 2011). Despite the observation that these three facets of social support tend to be moderately to strongly correlated (Caesens et al., 2014), variable-centered research has supported their differential predictive validity in relation to a variety of work outcomes (Newman, Thanacoody, \& Hui, 2012). Nevertheless, previous studies have mainly focused on the isolated effects of these different sources of social support, leaving unknown the nature of the most commonly occurring social support combinations, and the possible joint effects of these different combinations on employees' well-being, attitudes, and behaviors.

Yet, several scholars have claimed that these three sources of support should not be studied in isolation and were likely to have compensatory (i.e., employees require a certain amount of social support to function in an optimal manner, and this support can be supplied by a variety of sources) or mutually reinforcing (i.e., each source of social support helps to reinforce the benefits afforded by the other sources) effects (e.g., Ng \& Sorensen, 2008). Variable-centered tests of interaction effects and person-centered studies of employees' profiles can be used to examine these combined effects of different sources of perceived social support at work.

\section{Variable-Centered Tests of Interaction Effects among Sources of Social Support}

Variable-centered tests of interaction effects are specifically designed to assess the extent to which the effects of a variable can differ as a function of any other variable (e.g., Marsh, Hau, Wen, Nagengast, \& Morin, 2013). In tests of interactions, the observation that the effects associated with one source of workplace support tend to decrease as the level of support provided by the other sources increases would reveal compensatory effects. In contrast, observing that the effects of each source of workplace support increase when the level of support provided by the other sources also increases would reveal mutually reinforcing effects.

To our knowledge, only three studies have relied on tests of interaction effects to assess the combined effects of multiple sources of workplace support. In the first of those studies, Maertz, Griffeth, Campbell, and Allen (2007) showed that low PSS strengthened the negative relation between POS and turnover, while low POS similarly strengthened the negative relation between PSS and turnover. In a second study, Erickson and Roloff (2007) reported identical results in the prediction of organizational commitment among employees who survived downsizing. These results suggest that the effects of different sources of social support follow a compensatory model, where a certain amount of support is needed but may be supplied by the supervisor, the organization, or a combination of both. In contrast, in a third study, Simosi (2012) reported mutually reinforcing effects showing that the positive effects of PSS on training transfer were stronger when POS was high, whereas the positive effects of PCS on affective commitment were stronger when POS was high.

Despite the interest of these results, they remain limited in providing only a partial view of the reality. Indeed, variable-centered analyses seek to assess relations among variables as they occur, on the average, in the sample under study, without considering the possibility that subpopulations might exist among which these relations would differ. Although variable-centered tests of interactions (such as those used to study compensatory or mutually reinforcing effects) examine if the effects of one variable differ as a function of another one, these tests still assume that this interactive effect would equally apply to 
everyone. In addition, interactions rely on a linearity assumption according to which the effects of one variable varies in a linear manner as a function of the other. Polynomial models make it possible to incorporate non-linear terms (Edwards, 2009), but such models become almost impossible to interpret when more than two interacting predictors are considered. A more direct way of looking at the effects of balance and complementarity in the effects of different sources of social support could be achieved through person-centered analyses, to which we now turn our attention.

\section{Person-Centered Studies of Naturally Occurring Social Support Profiles}

Person-centered analyses, such as LPA, explicitly relax the assumption of linearity and population homogeneity, and are specifically designed to identify naturally occurring subpopulations (or profiles) of employees characterized by different configurations of social support at work (Meyer \& Morin, 2016; Morin, 2016). In fact, the discrepant results obtained in the context of previous research may simply reflect the lack of consideration of profile membership in the estimation of the relations between social support at work and the outcome variables. By focusing on relations among variables occurring, on the average, in a specific sample, variable-centered results could be impacted by the presence of subpopulations characterized by more extreme patterns of scores (e.g., a small profile characterized by very low levels of social support). We do not claim that variable-centered tests of interactions will necessarily be biased by ignoring the possible presence of subpopulations. However, we suggest that the person-centered analyses could be used to more specifically explore the underpinnings of unexpected or inconsistent variable-centered associations.

From a theoretical perspective, conservation of resources theory (Hobfoll, 1989; Hobfoll, Halbesleben, Neveu, \& Westman, 2018) is anchored into the assumption that employees seek to obtain, protect, and retain resources such as social support. These resources are further purported to facilitate or enable the acquisition or preservation of additional resources. In sum, this theory suggests that resources do not exist in isolation, but tend to aggregate to produce positive effects (e.g., Hobfoll et al., 2018), leading us to expect at least some profiles characterized by matching levels of perceived social support across sources (e.g., a profile with high levels of POS, PSS, and PCS). By suggesting that resources tend to support the further accumulation of resources, this theory could also explain how distinct sources of social support might come to generate mutually reinforcing effects on work outcomes as each source helps to maximize the benefits afforded by the others (Hobfoll, 1989). Unfortunately, no person-centered research on workers' social support has so far been conducted. However, indirect evidence coming from research conducted on related-constructs, as well as in other age-groups, may inform this question.

First, outside of the work context, research has shown that positive and supportive social relationships tend to give rise to other positive social relationships (Demaray, Malecki, Davidson, Hodgson, \& Rebus, 2005; Jager, 2011). Alternatively, divergence across sources of social support may occur for a variety of reasons, such as conflicts (Barrerra, Chassin, \& Rogosch, 1993), or the inability of some sources in providing adequate support (Jager, 2011). In a person-centered study of social support from teachers, peers, and parents conducted among adolescents, Ciarrochi, Morin, Sahdra, Litalien, and Parker (2017) found evidence for both convergence and divergence in social support. Additionally, they noted that "like wealth, perceived social support was not evenly distributed" (p. 1164), with few "socially rich" students receiving support from all sources, many "middle class" students receiving support from a subset of sources, and about a third of "socially poor", or isolated students receiving no social support from any source. They also found that most of the severe types of difficulties were concentrated in the socially isolated profile, with huge benefits associated with moving from zero to one source of support but only limited added value associated with being able to benefit from all three sources. Indeed, the conservation of resource theory (Hobfoll et al., 2018) suggests that the loss of resources is likely to be far more harmful for employees than the benefits associated with a comparable gain in resources. In particular, the rarer the resources, the more harmful losing them is likely to be. This principle suggests that the presence of at least one source of social support might be far more beneficial than the accumulation of additional sources. Given that exposure to proactive adult role models, and the establishment of positive social relationships with peers represent such important milestones for adolescents (Ryan \& Deci, 2000), results are likely to differ among a sample of working adults, an issue that we directly consider here. In the present study, we expect to identify a profile of employees with high levels of PCS, and moderate to low levels of POS and PSS, showing similar characteristics with the Peer Supported profile (high levels of peer support and moderately low levels 
of parental and teacher support) identified by Ciarrochi et al. (2017).

A second source of indirect evidence comes from the study of workplace commitment. Commitment is known to be anchored in the ability to share positive social relationships at work, and to feel supported by the target of the commitment (Rhoades \& Eisenberger, 2002). Prior person-centered studies on commitment (Meyer \& Morin, 2016) have shown that commitment to the organization and supervisor tend to co-vary within profiles of employees (Meyer, Morin, \& Vandenberghe, 2015), supportive of the idea that the supervisor might be viewed as the embodiment of the organization (Stinglhamber, Marique, Caesens, Hanin, \& De Zanet, 2015). In contrast, commitment to the supervisor and workgroup generally shows opposite patterns within profiles for most employees (Morin, Morizot et al., 2011). This personcentered research on commitment also shows that commitment related to specific entities presents strong associations with employees' perceptions of the social support received from these entities (Meyer et al., 2015). In line with these findings, a profile of employees characterized by low levels of social support from both the organization and their supervisor, and moderate to high levels of social support from their colleagues, should be identified in the current study.

More generally, the person-centered approach we relied on may allow us to address the two following questions: Can we identify several profiles characterized by matching levels of support across sources and other profiles characterized by different levels of support across sources? Is a profile with low levels of POS, PSS, and PCS associated with more negative outcomes than a profile with low levels of both POS and PSS, and moderate to high levels of PCS? Despite the fact that no research has ever looked at social support profiles in the work area, the theoretical underpinnings of OST (Eisenberger \& Stinglhamber, 2011) and conservation of resource theory (Hobfoll et al., 2018), coupled with indirect evidence coming from variable-centered research (e.g., Gillet et al., 2016; Kurtessis et al., 2017), interactive effects among sources of social support (Erickson \& Roloff, 2007; Maertz et al., 2007; Simosi, 2012), and person-centered research conducted among younger populations (e.g., Ciarrochi et al., 2017) or looking at workplace commitment (e.g., Meyer \& Morin, 2016), allow us to propose the following hypotheses:

Hypothesis 1. At least three profiles reflecting employees' perceptions of social support at work will be characterized by matching levels of support across sources (high, moderate, and low).

Hypothesis 2. Additional profiles reflecting employees' perceptions of social support at work will be characterized by well-differentiated configurations of social support across sources, particularly between PCS relative to POS and PSS.

Hypothesis 3. The most positive outcomes (higher levels of job satisfaction, commitment, and performance, and lower levels of emotional exhaustion and absenteeism) will be associated with the profiles characterized by the highest levels of social support across sources, while the most negative outcomes (lower levels of job satisfaction, commitment, and performance, and higher levels of emotional exhaustion and absenteeism) will be associated with the profiles characterized by the lowest levels of social support across sources.

Hypothesis 4. The associations between the social support profiles and work outcomes will be characterized by diminishing returns so that the greatest benefits will be associated with moving from zero source of social support to one, while reduced benefits will be associated with moving from one source to two, and negligible benefits will be associated with moving from two sources to three.

\section{Generalizability of Social Support Profiles}

Person-centered evidence requires an accumulation of studies to differentiate the main profiles that emerges systematically across samples, the peripheral profiles that emerge in specific contexts and samples, and the occasional profiles reflecting random sampling variations (Solinger, Van Olffen, Roe, \& Hofmans, 2013). Morin, Meyer, Creusier, and Biétry (2016) differentiate between four ways in which profiles can generalize, or differ, across samples. They refer to these ways as configural (same number of profiles), structural (profiles with the same nature), dispersion (degree of similarity among members of specific profiles observed across samples), and distributional (relative size of the profiles observed across samples) similarity. We felt that it was critical for this first empirical investigation of workers' social support profiles to carefully consider the generalizability of our results across two distinct convenience samples of employees, assessed via distinct methodological approaches. Interestingly, Ciarrochi et al. (2017) did not find evidence of within-sample differences occurring at the configural, structural, or dispersion levels when their sample of adolescents was re-assessed three years later, only observing a few relatively small distributional changes. Likewise, in their systematic review of person-centered 
research on profiles of workplace commitment conducted among working adults, Meyer and Morin (2016) report relatively strong evidence of profile similarity across studies, samples, and time periods. Based on these indirect sources of evidence, we did not expect configural or structural differences across samples in terms of workplace support profiles. We also expected the profiles to display similar associations with the matching outcome measures across samples (corresponding to Hypotheses 3 and 4). However, in the absence of prior guidance, we left as an open research question whether profile dispersion and distribution would be similar or not across samples.

Hypothesis 5. The identified profiles will display configural and structural similarity across samples, and will display a similar pattern of associations with the matching outcome variables.

\section{Participants and Procedures}

\section{Method}

We first had the opportunity to collect data, using paper-and-pencil questionnaires, among a sample of top managers and professionals. This sample was particularly interesting to consider given the relatively high level of autonomy that tends to characterize these types of employees. This level of autonomy might also make it harder for them to experience workplace support, and could also render these support experiences particularly beneficial. In contrast, our second sample was recruited via an online crowdsourcing platform and targeted a more diversified set of non-managerial workers.

Sample 1. Research assistants distributed a paper-based questionnaire to a convenience sample of 185 top managers and professionals (69 men; 116 women) from various organizations (e.g., hospitals, industries, sales, and services) located in France. Participants received a survey packet including the questionnaire, a cover letter explaining the study's purposes, and a consent form stressing that participation was anonymous and voluntary. Questionnaires required approximately 15 minutes to complete, and no incentive was offered. Completed questionnaires were returned to the research assistants. This sample included 26 participants employed in the public sector $(14.1 \%)$ and 159 employed in the private sector (85.9\%). Respondents were aged between 22 and 57 years $(M=32.29$, $S D=7.46)$, had an average organizational tenure of 6.10 years $(S D=7.17)$, and an average tenure in the current position of 3.19 years $(S D=3.56)$. Twelve participants had a high school diploma $(6.5 \%)$ and 173 had a university diploma (93.5\%).

Sample 2. A second sample of non-managerial employees was recruited using Prolific Academic, a UK crowdsourcing platform. Pre-screening criteria were used to recruit participants who: (1) had a minimum approval rate of $90 \%$ in the prolific system (an indicator of trustworthiness), (2) spoke English as their first language, (3) were working full-time or part-time, and (4) were not self-employed. Participants were informed that participation was voluntary and confidential, and that they could leave the survey at any time. Each participant received $£ 1.50$ upon the completion of the online questionnaire, which took an average of 15 minutes. The survey included two questions aiming to assess attention during completion (e.g., "It is important that you pay attention to our survey. Please tick strongly disagree"). These two questions were roughly located so as to split the questionnaire into three equal parts. At the end of the questionnaire, participants were also asked to indicate, "for scientific reasons", if they were really working for an organization. Sixty respondents were excluded from the participants' pool for failing at least one of those questions (44 participants failed the attention question 1, 26 failed the attention question 2, and 7 failed the last verification question, for a total of 77 errors made by 60 respondents). A total of 387 participants completed the survey and successfully responded to these three questions. Of these participants, $57.10 \%$ were women, $42.89 \%$ were men, and $43.60 \%$ held a bachelor degree. The average age and organizational tenure of these participants were respectively $34.30(S D=$ $10.98)$ and $5.57(S D=6.01)$ years. This project received approval from the University Research Ethics committee.

\section{Measures}

Due to space limitations, it was not possible to systematically assess all outcomes in both samples. For this reason, we retained Sample 1 for the assessment of participants' levels of emotional exhaustion and performance ( 6 items in total), and Sample 2 for the assessment of affective commitment (6 items). In order to ascertain the generalizability of the findings in a more systematic manner, the remaining outcomes (absenteeism and job satisfaction) were assessed in both samples. Yet, to maintain the stringency of our tests of generalizability, the mode of assessment of these two outcomes was also allowed to differ across samples (single-item measures in Sample 1 and multi-item measures in Sample 2). Unless otherwise specified, a 7point Likert-type scale ranging from "Strongly Disagree" to "Strongly Agree" was used to assess 
individuals' agreement with each item.

Perceived Support (Samples 1 and 2). POS was assessed using 4 items $(\alpha=.83$ in Sample 1 and .92 in Sample 2; e.g., "My organization really cares about my well-being") from Eisenberger et al.'s (1986). PSS and PCS were assessed using the same 4 items (PSS: $\alpha=.88$ in Sample 1 and .94 in Sample 2; e.g., "My supervisor really cares about my well-being"; PCS: $\alpha=.81$ in Sample 1 and .93 in Sample 2; e.g., "My colleagues really care about my well-being") adapted from the SPOS (Eisenberger et al., 1986) by replacing the word "organization" with the term "supervisor" or "colleagues".

Job Satisfaction (Samples 1 and 2). In Sample 1, we relied on a single-item measure (Shimazu, Schaufeli, Kamiyama, \& Kawakami, 2015) asking workers to report the extent to which they were satisfied with their job. Responses were made on a 4-point Likert-type scale (1- unsatisfied to 4- totally satisfied). In Sample 2, to see whether a multi-item scale would afford us a greater level of precision we relied on a 4-item scale developed by Eisenberger, Cummings, Armeli, and Lynch (1997) ( $\alpha=.93$; e.g., "All in all, I am very satisfied with my current job").

Absenteeism (Samples 1 and 2). In Sample 1, we relied on a single-item measure (Kessler et al., 2003) asking workers to report the number of entire work days they missed during the last year because of problems related to their physical or mental health. In Sample 2, absenteeism was assessed with two items developed by Johns $(2011 ; \alpha=.83$; i.e., "How many days were you absent from work in the past 12 months?" and "How many days were you absent from work in the past 12 months because you were sick or not feeling well?"). Participants indicated the numbers of days.

Emotional Exhaustion (Sample 1). Emotional exhaustion was assessed with a 5-item version $(\alpha=$ .88; e.g., "I feel emotionally drained by my work") of the Maslach Burnout Inventory-General Survey (Maslach \& Jackson, 1981). All items were rated on a 1 (strongly disagree) to 5 (strongly agree) response scale.

Performance (Sample 1). The one-item performance measure from the World Health Organization Health and Work Performance Questionnaire (Kessler et al., 2003) was used. Workers were asked to rate their usual job performance over the past four weeks on a 0 (the worst possible job performance a person could have on this job) to 10 (the top job performance on the job) scale.

Affective commitment to the organization (Sample 2). Affective commitment to the organization was assessed using Meyer, Allen, and Smith's (1993) 6-item scale $(\alpha=.90$; e.g., "I would be very happy to spend the rest of my career with this organization").

\section{Preliminary Analyses}

\section{Analyses}

Preliminary factor analyses were conducted to verify the psychometric properties of all multi-item measures. Factor scores (estimated in standardized units with $M=0, S D=1$ ) were saved from these measurement models and used as inputs for the main analyses (Meyer \& Morin, 2016). To ensure the comparability of profile indicators across samples, these factor scores were saved from invariant multigroup measurement models (Millsap, 2011). Factor scores do not fully control for measurement errors the way latent variables do, but provide a partial control by giving more weight to more reliable items (Skrondal \& Laake, 2001) and are able to preserve the underlying nature of the measurement model (e.g., invariance; Morin, Meyer, et al., 2016). Details on these models, their invariance across samples, and estimates of composite reliability for all constructs are reported in the online supplements. Correlations for all variables used in this research are reported in Table 1.

[Insert Table 1 about here]

\section{Main Analyses}

LPA were estimated using Mplus 7.4 robust maximum likelihood estimator (MLR) and Full Information Maximum Likelihood (FIML) to handle missing data (i.e., 0\% in Sample 1; 0 to $3.36 \%$ in Sample 2; Enders, 2010). To avoid converging on a local maximum, models were estimated with 5000 random start values, 1000 iterations, and 200 solutions retained for final optimization (Hipp \& Bauer, 2006). Models were first estimated separately in each sample using the three social support factor scores as profile indicators to verify whether the same number of profiles would be extracted in both samples. For each sample, we examined solutions including 1 to 8 profiles in which the means of the social support factors were freely estimated in all profiles. Despite the advantages of models in which indicators' variances are freely estimated (Peugh \& Fan, 2013), these alternative models converged on improper solutions or not at all. This suggests their inadequacy and overparameterization, and the superiority of our more parsimonious models (Chen, Bollen, Paxton, Curran, \& Kirby, 2001). 
To determine the optimal number of profiles, multiple sources of information were considered, including the substantive meaningfulness, theoretical conformity, and statistical adequacy of the solutions (Morin, 2016; Muthén, 2003). Statistical indices are available to support this decision: The Akaïke Information Criterion (AIC), the Consistent AIC (CAIC), the Bayesian Information Criterion (BIC), the sample-size Adjusted BIC (ABIC), the standard and adjusted Lo, Mendell and Rubin's (2001) Likelihood Ratio Tests (LMR/aLMR), and the Bootstrap Likelihood Ratio Test (BLRT). A lower value on the AIC, CAIC, $\mathrm{BIC}$, and ABIC suggests a better-fitting model. The aLMR and BLRT compare a $k$-class model with a $k$-1-class model. A significant $p$ value indicates that the $k$ - 1 -class model should be rejected in favor of a $k$-class model.

Simulation studies indicate that four of these indicators (CAIC, BIC, ABIC, and BLRT) are particularly effective, while the AIC and LMR/ALMR should not be used (for a recent review, see Diallo, Morin, \& Lu, 2016). These indicators will be reported to ensure a complete disclosure, but not used to select the optimal number of profiles. A recent simulation study (Diallo, Morin, \& Lu, 2017) suggests that the BIC and CAIC should be privileged under conditions of high entropy $(\geq .800)$, whereas the ABIC and BLRT perform better in conditions of low entropy $(\leq .600)$. Because these tests are sample size dependent (Morin, 2016), they may keep on suggesting the addition of profiles without reaching a minimum. In this situation, the point at which these indicators appear to reach a plateau can be used to suggest the optimal solution (Morin, Maïano et al., 2011).

Once the optimal number of profiles was selected for each sample, we integrated the two retained LPA solutions (one for each sample) into a single multi-group LPA model to test the similarity of the profiles across samples. These tests were conducted following the sequential strategy proposed by Morin, Meyer et al. (2016): (a) configural similarity (same number of profiles); (b) structural similarity (same means on the profile indicators, revealing profiles with the same structure); (c) dispersion similarity (same degree of within-profile variance on the profile indicators); and (d) distributional similarity (same profile size). Morin, Meyer et al. (2016) suggest that at least two indices out of the CAIC, BIC, and ABIC should be lower for the more "similar" model for the hypothesis of profile similarity to be supported.

A strong assumption of LPA with covariates is that the nature of the profiles should remain unaffected by inclusion of the covariates (Diallo et al., 2017). To ensure that this did not happen, outcomes levels were contrasted across profiles separately in both samples using AUXILIARY (DCON) function (Asparouhov \& Muthén, 2014). For purely descriptive purposes, we also assessed associations between demographic characteristics (sex, age, and organizational tenure) and profile membership. Results from these tests are reported at the end of the online supplements.

\section{Latent Profile Solutions}

\section{Results}

The fit indices associated with the LPA estimated separately in both samples are reported in the top and middle sections of Table 2. These results reveal a relatively high entropy (.798 to .846 across samples and models), indicating a relatively high level of classification accuracy, and suggesting that the BIC and CAIC should be favored (Diallo et al., 2017). In Sample 1, both the CAIC and the BIC reached their lowest point at 5 profiles, although the ABIC kept on suggesting the addition of profiles and the BLRT supported the 7-profile solution. Still, the decreases in ABIC reached a plateau after the 5-profile solution. In Sample 2, the results are not as clear, with the BIC, ABIC, and BLRT keeping on suggesting the addition of profiles, and the CAIC reaching its lowest point at 7 profiles. Still, the decreases in CAIC, BIC, and ABIC values reached a plateau around the 5-profile solution. We thus carefully examined the 5-profile solution for both samples, as well as bordering 4- and 6-profile solutions. This examination showed that these solutions were fully proper statistically, revealed a high level of similarity across samples, and indicated that moving from 4 to 5 profiles added a meaningfully different (and relatively large) profile to the solution in both samples, whereas moving from 5 to 6 profile solution resulted in the arbitrary division of one profile into two similar (and smaller) ones. The 5-profile solution was thus retained for both samples, supporting its configural similarity.

[Insert Table 2 about here]

A multi-group LPA model of configural similarity including 5 profiles per sample was then estimated. The fit indices from all multiple-group LPAs are reported in the bottom section of Table 2 . These results show that the addition of similarity constraints across samples systematically resulted in lower values on the CAIC, BIC, and ABIC, thereby supporting the distributional similarity of the 
profiles. This model of distributional similarity was retained for interpretation and for the next stages of analyses and is illustrated in Figure 1. The exact within-profile means and variances are reported in Table S4 of the online supplements, while the classification accuracy of participants into their most likely profile is reported in Table S5 of the online supplements. These results indicate a high classification accuracy, varying from $83.2 \%$ to $93.7 \%$ across profiles and samples.

[Insert Figure 1 about here]

Members of Profile 1 mention receiving moderately high levels of social support from the organization and their supervisor, and moderate levels of social support from their colleagues. This moderately supported profile characterizes about a third (33.40\%) of the participants across samples. Members of Profile 2 indicate receiving very low levels of social support from both the organization and their supervisor, and moderately low levels of social support from their colleagues. This isolated profile characterizes $13.68 \%$ of the participants across samples. Members of Profile 3 also mention receiving very low levels of social support from the organization, but for them this is coupled with a moderately high level of social support from the supervisor, and moderate levels of social support from their colleagues. This supervisor supported profile is the smallest and characterizes $4.63 \%$ of the participants across samples. Members of Profile 4 report receiving moderately low levels of social support from all sources. This weakly supported profile characterizes about a fourth $(23.12 \%)$ of the participants across samples. Finally, participants from Profile 5 feel highly supported by all sources. This highly supported profile characterizes about a fourth (25.18\%) of participants across samples. Generally, these profiles support Hypotheses 1 and 2, and their similarity across samples supports Hypothesis 5.

\section{Outcomes of Profile Membership}

Outcomes were finally included, separately for each sample, to the final retained model of distributional similarity. The within-profile means of each outcome in each sample are reported in Table 3 and illustrated in Figures 2 (Sample 1) and 3 (Sample 2). In Sample 1, the highest levels of emotional exhaustion and absenteeism were observed in Profile 2 (isolated), with few differences between the remaining profiles. Profile 1 (moderately supported) also presented higher levels of emotional exhaustion relative to Profile 5 (highly supported). In terms of more desirable outcomes, the highest levels of job satisfaction and performance were generally observed in Profile 5 (highly supported), followed by Profiles 1 (moderately supported) and 4 (weakly supported), with the lowest levels observed in Profiles 2 (isolated) and 3 (supervisor supported). In Sample 2, absenteeism did not significantly differ across profiles. For the more desirable outcomes, the results replicated those from Sample 1, showing that levels of affective commitment and job satisfaction were highest in Profile 5 (highly supported), followed by Profile 1 (moderately supported), and then equally by Profiles 3 (supervisor supported) and 4 (weakly supported), with the lowest levels among Profile 2 (isolated). Generally, these results thus provided support to Hypotheses 3 and 4, and the similarity of the profiles-outcomes associations across samples also supported Hypothesis 5.

[Insert Table 3 about here]

[Insert Figures 2 and 3 about here]

\section{Discussion}

In this study, we relied on a person-centered multidimensional conceptualization of perceived social support (POS, PSS, and PSS). Many studies have shown that, despite their distinctive nature, POS, PSS, and PCS are positively related with one another (e.g., Caesens et al., 2014). However, little attention has been allocated to understanding the joint effects of these three sources of social support (Simosi, 2012). The person-centered approach adopted in this study provided us with a way to assess how these three sources of social support at work are combined among different profiles of employees, and the relative consequences of membership into these various profiles. By relying on a multidimensional conceptualization of perceived workplace support, encompassing POS, PSS, and PSS (e.g., $\mathrm{Ng} \&$ Sorensen, 2008), we extended past research studying these different sources of social support at work in isolation (Eisenberger \& Stinglhamber, 2011). More specifically, by relying on a personcentered approach, we extended the social support literature in several ways by showing that: (a) individuals generally perceive a climate of social support that generalizes across sources (POS, PSS, PCS) but can also perceive dissimilar levels of support across sources, and (b) these profiles do share associations with work-related outcomes (job satisfaction, emotional exhaustion, affective commitment to the organization, performance, and absenteeism), although not all of the observed associations could 
have been expected from previous variable-centered research evidence.

Our results revealed five distinct social support profiles that fully generalized across among two independent samples of workers, thus supporting Hypothesis 5. Three of these profiles met our expectations (Hypothesis 1), based on indirect research evidence (e.g., Ciarrochi et al., 2017; Meyer et al., 2015), and displayed converging levels of social support across sources. Specifically, the weakly supported, moderately supported, and highly supported profiles were respectively characterized by low, moderate, and high levels of social support across sources. These findings suggest that perceived social support tends to be characterized by matching levels on POS, PSS, and PCS for most employees $(81.7 \%)$. These profiles also corroborate the resource accumulation principle of conservation of resources theory (e.g., Hobfoll et al., 2018), which states that resources tend to aggregate rather than to operate in isolation. These results are also in line with the trickle-down effects of support (Frear, Donsbach, Theilgard, \& Shanock, 2017), according to which levels of social support from any source tends to spread to other sources due to the presence of a global social support culture in specific workplaces. The trickle-down effects thus suggest that the organization sets a social support culture, creating an alignment between the level of support it provides to its employees, and the level of support supervisors and colleagues are themselves expected to provide. In contrast, low support from the organization may signal that social support is not part of the organizational culture, with consequences on employees' behaviors and perceptions of support from all other sources.

Also matching our expectations (Hypothesis 2; Ciarrochi et al., 2017; Meyer \& Morin, 2016), we identified two profiles showing diverging levels of social support across sources. The isolated profile was characterized by very low POS and PSS, and moderately low PCS, while the supervisor supported profile was characterized by very low POS, moderately high PSS, and moderate PCS. This result lends support to prior variable-centered results showing the importance of distinguishing these three sources of support (Simosi, 2012), and the assertion that employees can develop distinct perceptions of the social support from distinct entities (Eisenberger \& Stinglhamber, 2011).

Our findings are also in line with those from person-centered commitment research (Meyer \& Morin, 2016), shedding new light on the supervisor's organizational embodiment construct defined as the extent to which employees perceive their supervisor as sharing a common identity with the organization (e.g., Stinglhamber et al., 2015). More precisely, research on supervisor's organizational embodiment suggests that the strength of the relation between a supervisor-related variable and a matching organization-related variable should depend on the extent to which the employee considers that his or her supervisor embodies the organization (Stinglhamber et al., 2015). Without this embodiment, supervisor's practices "would be attributed primarily to the individual characteristics of the supervisor, with only modest credit given to the organization" (Stinglhamber et al., 2015, p. 588). The supervisor supported profile appears to reflect this situation. In contrast, no evidence was found for a colleagues-supported profile (i.e., high PCS but low POS/PSS), suggesting that high PCS might be limited to workers already exposed to adequate support from their organization and supervisor.

\section{Outcomes of Social Support Profiles}

The identified social support profiles also presented well-differentiated associations with the outcomes considered here that generally supported Hypotheses 3 and 4, and showed a high level of similarity across samples. Specifically, the isolated profile was found to be associated with the worst outcomes (i.e., higher levels of emotional exhaustion and absenteeism, and lower levels of job satisfaction, performance, and affective commitment), while the highly supported profile was associated with the most positive outcomes. These results suggest that the key determinant of work outcomes seems to be the presence, or absence, of social support at work, rather than the specific source of social support. These results are interesting given that previous variable-centered studies showed that POS, PSS, and PCS could have compensatory (Erickson \& Roloff, 2007) or mutually reinforcing (Simosi, 2012) effects. In contrast, the present results rather support the idea that social support tends to aggregate across sources for a majority of employees, and support the idea that global levels of social support at work tend to be positively related to job satisfaction (Eisenberger et al., 1997), performance (Liaw, Chi, \& Chuang, 2010), and affective commitment (Stinglhamber et al., 2015), and negatively associated with emotional exhaustion (Avanzi, Schuh, Fraccaroli, \& van Dick, 2015) and absenteeism (Eisenberger et al., 1986).

Moreover, although our results support the idea that undesirable outcomes tend to be associated with low levels of POS, PSS, and PCS (Kurtessis et al., 2017), levels of affective commitment and job 
satisfaction observed in the supervisor supported profile were found to be lower (Sample 2) or similar (Sample 1) to those observed in the weakly supported profile. Thus, lacking support from colleagues and organization is associated with lower levels of employees' affective commitment and job satisfaction. This result also suggests that supervisors are not able to fully compensate from a lack of social support provided by the other two sources (organization and colleagues). This observation represents an important new insight afforded by the present study. The conservation of resource theory (Hobfoll, 1989) is informative in this regard. First, it suggests that resources tend to support the further accumulation of resources and may explain why low levels of POS and PCS or low scores on the three distinct sources of social support are associated with the worst outcomes. Moreover, the loss of resources is likely to be far more detrimental for workers than the benefits associated with a comparable gain in resources (Hobfoll et al., 2018), suggesting that the presence of at least one source of social support (PSS) might be sufficient to compensate from low levels of POS and PCS. Our results are not in line with this hypothesis and the results from Ciarrochi et al.'s (2017) study showing considerable benefits when moving from zero to one source of social support. Future research is thus needed to better understand the costs and benefits of supervisor support, especially when considering the possible compensatory role of PSS for employees exposed to low levels of POS and PCS.

\section{Limitations and Future Research}

Despite their interest, these results present limitations that should be addressed in future research. First, our research is based on a cross-sectional design, making it impossible to reach clear conclusions regarding the directionality of the associations among constructs. As such, future research would benefit from longitudinal designs allowing for a more precise investigation of the stability and directionality of these associations. Second, our reliance on two convenience samples of European workers made it hard to assess the extent to which our results would generalize to more general populations of workers. Our demonstration that the observed results generalize across two distinct samples, recruited via different methods and procedures, somehow alleviate these concerns. Still, it remains important for future research to rely on more representative samples. Third, even though the scales used to measure each outcome were similar across samples, there were not exactly the same. Indeed, we used single-item measures to assess job satisfaction, performance, and absenteeism in Sample 1. Yet, it is well known that such measures tend to be less reliable than multi-item measures, and not as good at providing a complete content coverage of the construct under study. Although we compensated for the use of singleitem scales in Sample 1 by assessing outcomes with more complete scales in Sample 2, our findings should be replicated using more solid measurement scales. In particular, we solely relied on self-report measures, which might be impacted by social desirability and self-report biases. Fortunately, as noted by Meyer and Morin (2016), shared method variance is not unlikely to play a role in person-centered results. Fourth, Sample 2 participants were recruited using the crowdsourcing prolific academic platform. Landers and Behrend (2015) indicated concerns associated with similar platforms (e.g., MTurk) related to the: (1) repeated participation of individuals, (2) monetary compensation that can affect motivation, (3) potential selection bias for participants, and (4) representativity of the sample. However, they mentioned that these platforms were "neither better nor worse than other more common convenient samples" (p. 21), and that "if we intend to create theory broadly applicable across organizational contexts, MTurk and similar samples may prove superior to those collected from single convenient organizations" (p. 18).

\section{Practical Implications and Conclusions}

Several recommendations for practitioners emerge from the present findings. First, the relative prevalence of the various profiles identified here revealed that a lot remains to be done to increase perceptions of social support in the workplace. In both samples, only $25 \%$ of employees reported to be supported by all three sources. That means that $75 \%$ of employees feel moderately or not supported by their organization, supervisor, and colleagues. In particular, close to $40 \%$ of the employees report moderately low to very low levels of social support from all three sources. Interestingly, these results are well-aligned with those observed by Ciarrochi et al. (2017) among high school students, showing a small profile of "socially rich" employees, a large "middle class" of employees supported by a subset of sources, and an equally large profile of "socially-poor" employees. More importantly, our results further reveal that highly supported profile reported the highest levels of job satisfaction, affective commitment, and performance, thus reinforcing the importance of perceived support in the workplace. Managers and practitioners should care about the extent to which their employees perceive support in 
the workplace and try to foster these perceptions.

Our results also supported the idea that, in general, the three sources of social support tend to be aligned with one another for most employees. This observation is aligned with the trickle-down effect (e.g., Eisenberger \& Stinglhamber, 2011), suggesting that social support from one source tends to spread out to other sources, and with the idea that POS may elicit among employees the belief that the organization expects them to be supportive toward others (e.g., Frear et al., 2017). These observations suggest that initiatives aiming to increase social support at work are likely to have widespread benefits. Among possible ways to achieve this objective, top management might promote a supportive culture within their organization, for instance, by providing to employees the resources or materials they need to perform they job effectively, by providing useful training and developmental programs, by reducing work overload, by providing assurance of security during stressful times, and by promoting justice and fairness in the way policies are implemented and rewards distributed (Eisenberger \& Stinglhamber, 2011). Additionally, supervisors could also be trained in order to be supportive toward their subordinates. Recently, Gonzalez-Morales, Kernan, Becker, and Eisenberger (2018) developed and provided evidence for the efficacy of a brief supervisor support training program including four basic strategies (i.e., benevolence, sincerity, fairness, and experiential processing). Several scholars also suggested that management should encourage supervisors to be active in their supportive role toward their subordinates, for instance, by providing daily feedback (e.g., Newman et al., 2012). Finally, in order to foster a climate of support among colleagues, managers may implement informal mentoring activities among colleagues, as well as help to organize informal social events after work aiming to encourage the development of stronger social relationships (Newman et al., 2012). Furthermore, managers should foster and encourage a culture where positive and supportive interactions between colleagues and across organizational levels, becomes the norm (Newman et al., 2012). 


\section{References}

Asparouhov, T., \& Muthén, B.O. (2014). Auxiliary variables in mixture modeling. Structural Equation Modeling, 21, 1-13.

Avanzi, L., Schuh, S.C., Fraccaroli, F., \& van Dick, R. (2015). Why does organizational identification relate to reduced employee burnout? The mediating influence of social support and collective efficacy. Work \& Stress, 29, 1-10.

Barrerra, M., Chassin, L., \& Rogosch, F. (1993). Effects of social support and conflict on children of alcoholic and nonalcoholic fathers. Journal of Personality and Social Psychology, 64, 602-612.

Berry, C.M., Lelchook, A.M., \& Clark, M.A. (2012). A meta-analysis of the interrelationships between employee lateness, absenteeism, and turnover: Implications for models of withdrawal behavior. Journal of Organizational Behavior, 33, 678-699.

Bowling, N.A., Khazon, S., Meyer, R.D., \& Burrus, C.J. (2015). Situational strength as a moderator of the relationship between job satisfaction and job performance: A meta-analytic examination. Journal of Business and Psychology, 30, 89-104.

Caesens, G., Stinglhamber, F., \& Luypaert, G. (2014). The impact of work engagement and workaholism on well-being: The role of work-related social support. Career Development International, 19, 813-835.

Chen, F., Bollen, K., Paxton, P., Curran, P., \& Kirby, J. (2001). Improper solutions in structural question models. Sociological Methods \& Research, 29, 468-508.

Ciarrochi, J., Morin, A.J.S., Sahdra, B., Litalien, D., \& Parker, P.D. (2017). A Longitudinal personcentered perspective on youth social support: Relations with psychological wellbeing. Developmental Psychology, 53, 1154-1169.

Demaray, M., Malecki, C., Davidson, L., Hodgson, K., \& Rebus, J. (2005). The relation between social support and student adjustment. Psychology in the Schools, 42, 691-706.

Demerouti, E., Bakker, A.B., \& Leiter, M. (2014). Burnout and job performance: The moderating role of selection, optimization, and compensation strategies. Journal of Occupational Health Psychology, 19, 96-107.

Diallo, T.M.O, Morin, A.J.S., \& Lu, H. (2016). Impact of misspecifications of the latent variancecovariance and residual matrices on the class enumeration accuracy of growth mixture models. Structural Equation Modeling, 23, 507-531.

Diallo, T.M.O., Morin, A.J.S., \& Lu, H. (2017). The impact of total and partial inclusion or exclusion of active and inactive time invariant covariates in growth mixture models. Psychological Methods, $22,166-190$.

Edwards, J.R. (2009). Latent variable modeling in congruence research: Current problems and future directions. Organizational Research Methods, 12, 34-62.

Eisenberger, R., Cummings, J., Armeli, S., \& Lynch, P. (1997). Perceived organizational support, discretionary treatment, and job satisfaction. Journal of Applied Psychology, 82, 812-820.

Eisenberger, R., Huntington, R., Hutchison, S., \& Sowa, D. (1986). Perceived organizational support. Journal of Applied Psychology, 71, 500-507.

Eisenberger, R., \& Stinglhamber, F. (2011). Perceived organizational support: Fostering enthusiastic and productive employees. Washington, DC: APA Books.

Eisenberger, R., Stinglhamber, F., Vandenberghe, C., Sucharski, I., \& Rhoades, L. (2002). Perceived supervisor support: Contributions to perceived organizational support and employee retention. Journal of Applied Psychology, 87, 565-573.

Enders, C.K. (2010). Applied missing data analysis. New York: Guilford.

Erickson, R.A., \& Roloff, M.E. (2007). Reducing attrition after downsizing: Analyzing the effects of organizational support, supervisor support, and gender on organizational commitment. International Journal of Organizational Analysis, 15, 35-55.

Frear, K.A., Donsbach, J., Theilgard, N., \& Shanock, L.R. (2017). Supported supervisors are more supportive, but why? Journal of Business and Psychology, 32, 1-15.

Gillet, N., Fouquereau, E., Huyghebaert, T., \& Colombat, P. (2016). Effets du soutien organisationnel perçu et des caractéristiques de l'emploi sur l'anxiété au travail et l'épuisement professionnel: Le rôle médiateur de la satisfaction des besoins psychologiques. Psychologie Française, 61, 73-81.

Gong, Y., Law, K.S, Chang, S., \& Xin, K.R. (2009). Human resource management and firm performance: The differential role of managerial affective and continuance commitment. Journal 
of Applied Psychology, 94, 263-275.

Gonzalez-Morales, M., Kernan, M.C., Becker, T.E., \& Eisenberger, R. (2018). Defeating abusive supervision: Training supervisors to support subordinates. Journal of Occupational Health Psychology, 23, 151-162.

Hakanen, J.J., Peeters, M.C.W., \& Schaufeli, W.B. (2018). Different types of employee well-being across time and their relationships with job crafting. Journal of Occupational Health Psychology, 23, 289-301.

Hipp, J.R., \& Bauer, D.J. (2006). Local solutions in the estimation of growth mixture models. Psychological Methods, 11, 36-53.

Hobfoll, S.E. (1989). Conservation of resources: A new attempt at conceptualizing stress. American Psychologist, 44, 513-524

Hobfoll, S.E., Halbesleben, J., Neveu, J.-P., \& Westman, M. (2018). Conservation of resources in the organizational context: The reality of resources and their consequences. Annual Review of Organizational Psychology and Organizational Behavior, 5, 103-128.

Jager, J. (2011). Convergence and nonconvergence in the quality of adolescent relationships and its association with adolescent adjustment and young-adult relationship quality. International Journal of Behavioral Development, 35, 497-506.

Johns, G. (2011). Attendance dynamics at work: The antecedents and correlates of presenteeism, absenteeism, and productivity loss. Journal of Occupational Health Psychology, 16, 483-500.

Kessler, R.C., Barber, C., Beck, A., Berglund, P., Cleary, P.D., McKenas, D., \& Pronk, N. (2003). The world health organization health and work performance questionnaire. Journal of Occupational and Environmental Medicine, 45, 156-174.

Kurtessis, J.N., Eisenberger, R., Ford, M.T., Buffardi, L.C., Stewart, K.A., \& Adis, C.S. (2017). Perceived organizational support a meta-analytic evaluation of organizational support theory, Journal of Management, 43, 1854-1884.

Landers, R.N., \& Behrend, T.S. (2015). An inconvenient truth: Arbitrary distinctions between organizational, Mechanical Turk, and other convenience samples. Industrial and Organizational Psychology: Perspectives on Science and Practice, 8, 142-164.

Liaw, Y.J., Chi, N.W., \& Chuang, A. (2010). Examining the mechanisms linking transformational leadership, employee customer orientation, and service performance: The mediating roles of perceived supervisor and coworker support. Journal of Business and Psychology, 25, 477-492.

Lo, Y., Mendell, N.R., \& Rubin, D.B. (2001). Testing the number of components in a normal mixture. Biometrika, 88, 767-778.

Maertz, C.P., Griffeth, R.W., Campbell, N.S., Allen, D.G. (2007). The effects of perceived organizational support and perceived supervisor support on employee turnover. Journal of Organizational Behavior, 28, 1059-1075.

Marsh, H.W., Hau, K.-T., Wen, Z., Nagengast, B., \& Morin, A.J.S. (2013). Moderation. In T.D. Little (Ed.), Oxford handbook of quantitative methods, Vol. 2 (pp. 361-386), New York: Oxford University Press.

Maslach, C., \& Jackson, S.E. (1981). The measurement of experienced burnout. Journal of Organizational Behavior, 2, 99-113.

Meyer, J.P., Allen, N.J., \& Smith, C.A. (1993). Commitment to organizations and occupations: Extension and test of a three-component conceptualization. Journal of Applied Psychology, 78, 538-551.

Meyer, J.P., \& Morin, A.J.S. (2016). A person-centered approach to commitment research: Theory, research, and methodology. Journal of Organizational Behavior, 37, 584-612.

Meyer, J.P., Morin, A.J.S., \& Vandenberghe, C. (2015). Dual commitment to organization and supervisor: A person-centered approach. Journal of Vocational Behavior, 88, 56-72.

Millsap, R.E. (2011). Statistical approaches to measurement invariance. New York: Taylor \& Francis.

Morin, A J.S. (2016). Person-centered research strategies in commitment research. In J.P. Meyer (Ed.), The handbook of employee commitment (pp. 490-508). Cheltenham, UK: Edward Elgar.

Morin, A J.S., Maïano, C., Nagengast, B., Marsh, H.W., Morizot, J., \& Janosz, M. (2011). Growth mixture modeling of adolescents trajectories of anxiety: The impact of untested invariance assumptions on substantive interpretations. Structural Equation Modeling, 18, 613-648.

Morin, A.J.S., Meyer, J.P., Creusier, J., \& Biétry, F. (2016). Multiple-group analysis of similarity in latent profile solutions. Organizational Research Methods, 19, 231-254.

Morin, A.J.S., Morizot, J., Boudrias, J.-S., \& Madore, I. (2011). A multifoci person-centered perspective 
on workplace affective commitment: A latent profile/factor mixture analysis. Organizational Research Methods, 14, 58-90.

Muthén, B. (2003). Statistical and substantive checking in growth mixture modeling. Psychological Methods, 8, 369-377.

Newman, A., Thanacoody, R., \& Hui, W. (2012). The effects of perceived organizational support, perceived supervisor support and intra-organizational network resources on turnover intentions. Personnel Review, 41, 56-72.

Ng, T.W., \& Sorensen, K.L. (2008). Toward a further understanding of the relationships between perceptions of support and work attitudes: A meta-analysis. Group \& Organization Management, 33, 243-268.

Peugh, J., \& Fan, X. (2013). Modeling unobserved heterogeneity using latent profile analysis: A Monte Carlo simulation. Structural Equation Modeling, 20, 616-639.

Rhoades, L., \& Eisenberger, R. (2002). Perceived organizational support: A review of the literature. Journal of Applied Psychology, 87, 698-714.

Ryan, R.M., \& Deci, E.L. (2000). Self-determination theory and the facilitation of intrinsic motivation, social development, and well-being. American Psychologist, 55, 68-78.

Schmid, J.A., Jarczok, M.N., Sonntag, D., Herr, R.M., Fischer, J.E., \& Schmidt, B. (2017). Associations between supportive leadership behavior and the costs of absenteeism and presenteeism: An epidemiological and economic approach. Journal of Occupational and Environmental Medicine, 59, 141-147.

Shimazu, A., Schaufeli, W.B., Kamiyama, K., \& Kawakami, N. (2015). Workaholism vs. work engagement: The two different predictors of future well-being and performance. International Journal of Behavioral Medicine, 22, 18-23.

Simosi, M. (2012). Disentangling organizational support construct: The role of different sources of support to newcomers' training transfer and organizational commitment. Personnel Review, 41, 301-320.

Skrondal, A., \& Laake, P. (2001). Regression among factor scores. Psychometrika, 66, 563-576.

Solinger, O.N., Van Olffen, W., Roe, R.A., \& Hofmans, J. (2013). On becoming (un)committed: A taxonomy and test of newcomer onboarding scenarios. Organization Science, 24, 1640-1661.

Steffens, N.K., Yang, J., Jetten, J., Haslam, S.A., \& Lipponen, J. (2018). The unfolding impact of leader identity entrepreneurship on burnout, work engagement, and turnover intentions. Journal of Occupational Health Psychology, 23, 373-387.

Stinglhamber, F., Bentein, K., \& Vandenberghe, C. (2002). Extension of the three-component model of commitment to five foci: Development of measures and substantive test. European Journal of Psychological Assessment, 18, 123-138.

Stinglhamber, F., Marique, G., Caesens, G., Hanin, D., \& De Zanet, F. (2015). The influence of transformational leadership on followers' affective commitment: The role of perceived organizational support and supervisor's organizational embodiment. Career Development International, 20, 583-603.

Yu, K., Lin, W., Wang, L., Ma, J., Wei, W., Wang, H., Guo, W., \& Shi, J. (2016). The role of affective commitment and future work self salience in the abusive supervision-job performance relationship. Journal of Occupational and Organizational Psychology, 89, 28-45. 


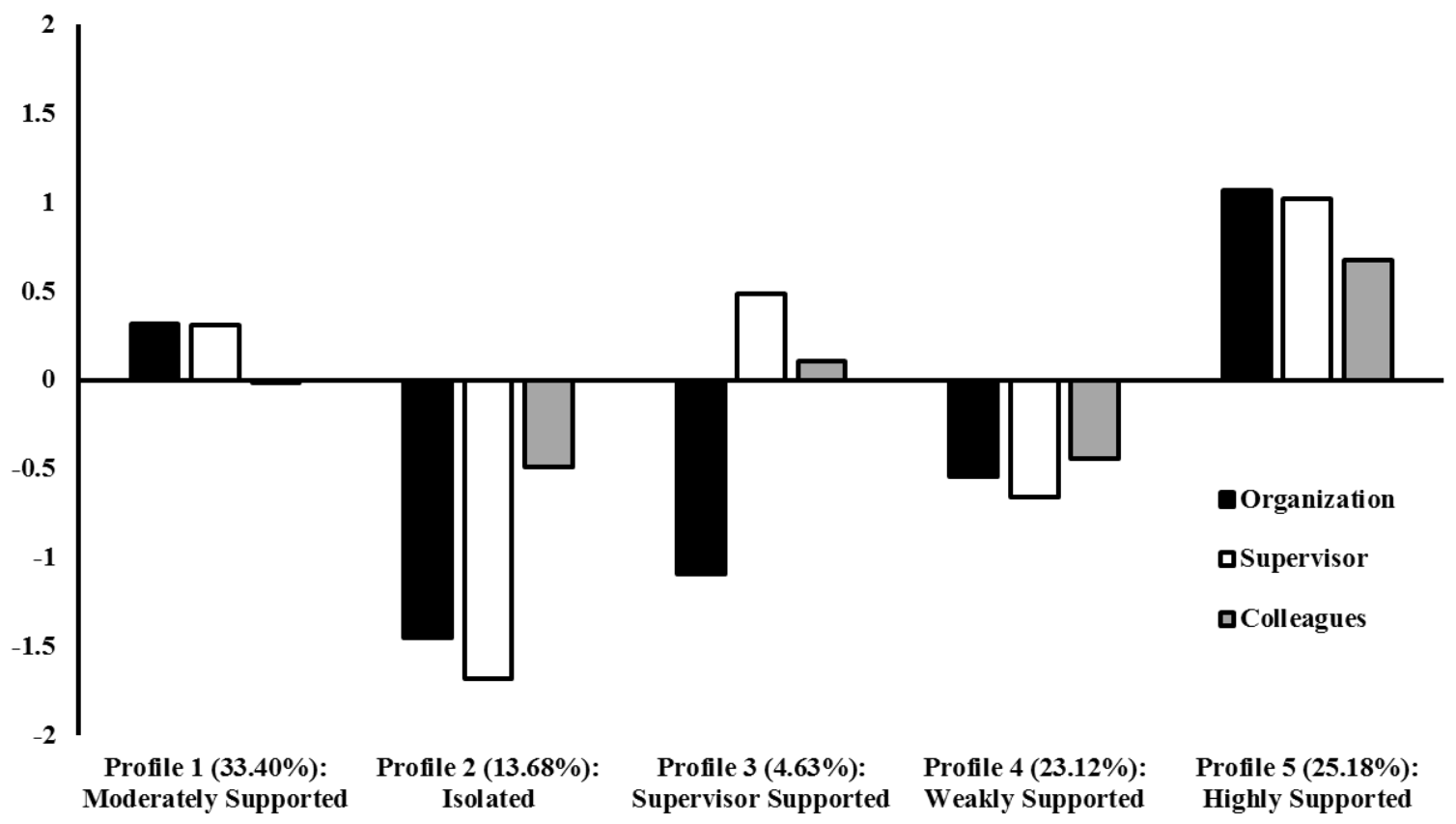

Figure 1. Final 5-Profile Solution Identified in both Samples (Distributional Similarity)

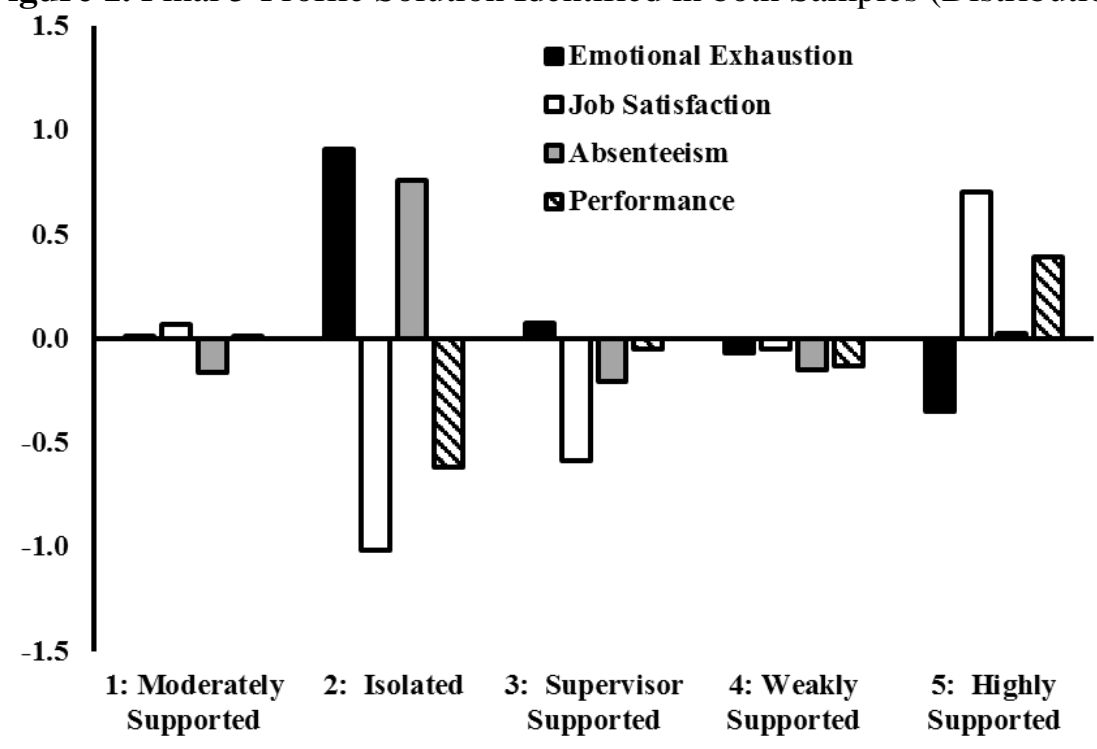

Figure 2. Standardized Outcome Levels in the Final 5-Profile Solution (Sample 1)

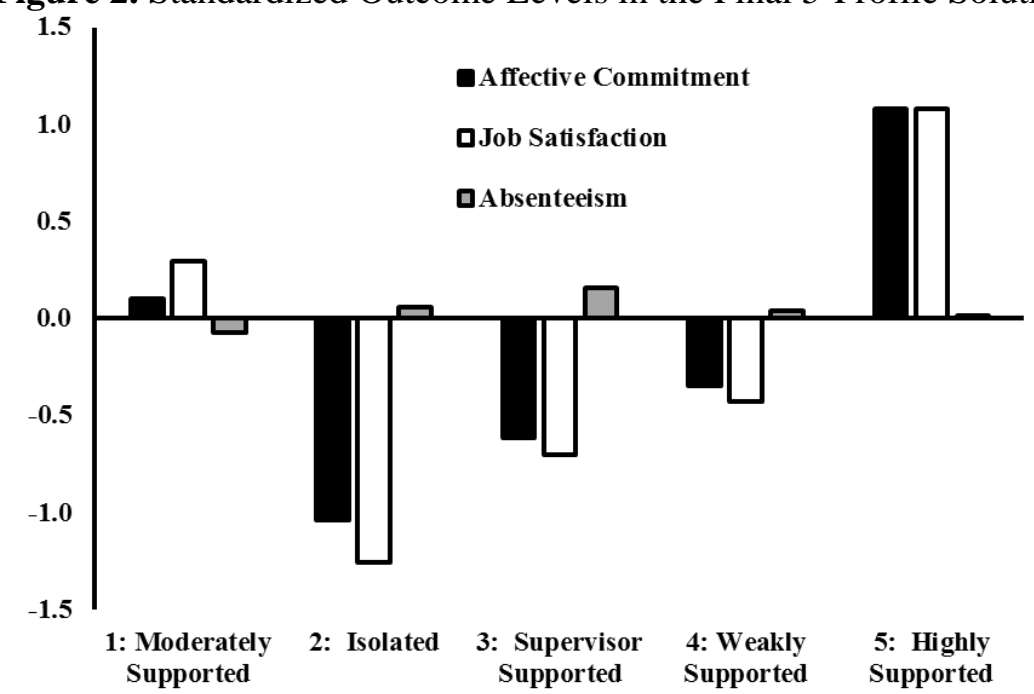

Figure 3. Standardized Outcome Levels in the Final 5-Profile Solution (Sample 2) 


\section{Table 1}

Correlations between Variables

\begin{tabular}{|c|c|c|c|c|c|c|c|c|c|c|}
\hline Sample 1 & 1 & 2 & 3 & 4 & 5 & 6 & 7 & 8 & 9 & 10 \\
\hline 1. Sex & - & & & & & & & & & \\
\hline 2. Age & -.048 & - & & & & & & & & \\
\hline 3. Organizational tenure & -.078 & $.823 * *$ & - & & & & & & & \\
\hline 4. Organizational support $\dagger$ & -.135 & -.065 & -.142 & - & & & & & & \\
\hline 5. Supervisor support $\dagger$ & -.070 & -.139 & $-.179 *$ & $.737 * *$ & - & & & & & \\
\hline 6. Colleagues support $\uparrow$ & -.009 & -.140 & -.064 & $.207 * *$ & $.255 * *$ & - & & & & \\
\hline 7. Emotional exhaustion $\dagger$ & .127 & .005 & .041 & $-.260 * *$ & $-.332 * *$ & -.037 & - & & & \\
\hline 8. Job satisfaction & $-.216 * *$ & .000 & -.041 & $.483 * *$ & $.452 * *$ & .110 & $-.435 * *$ & - & & \\
\hline 9. Performance & $-.152 *$ & .116 & .028 & $.273 * *$ & $.280 * *$ & .121 & $-.239 * *$ & $.328 * *$ & - & \\
\hline 10. Absenteeism & .057 & $.201 * *$ & $.258 * *$ & -.092 & -.131 & -.031 & $210 * *$ & -.121 & $-.152 *$ & - \\
\hline Sample 2 & 1 & 2 & 3 & 4 & 5 & 6 & 7 & 8 & 9 & \\
\hline 1. Sex & - & & & & & & & & & \\
\hline 2. Age & -.040 & - & & & & & & & & \\
\hline 3. Organizational tenure & -.014 & $.562 * * *$ & - & & & & & & & \\
\hline 4. Organizational support $\dagger$ & .053 & -.080 & -.037 & - & & & & & & \\
\hline 5. Supervisor support $\dagger$ & .025 & -.083 & -.007 & $.789 * * *$ & - & & & & & \\
\hline 6. Colleagues support $\uparrow$ & $-.112 *$ & .002 & .087 & $.441 * * *$ & $.445^{* * *}$ & - & & & & \\
\hline 7. Affective commitment $\uparrow$ & -.030 & $.107 *$ & $.192 * *$ & $.655 * * *$ & $.602 * * *$ & $.471 * * *$ & - & & & \\
\hline 8. Job satisfaction $\dagger$ & .023 & -.049 & .062 & $.717 * * *$ & $.699 * * *$ & $.424 * * *$ & $.776 * * *$ & - & & \\
\hline 9. Absenteeism $\dagger$ & -.067 & .074 & $.208 * * *$ & -.026 & -.023 & .018 & .077 & -.005 & - & \\
\hline
\end{tabular}

Note. $* p<.05 ; * * p<.01 ; \uparrow$ Variables estimated from factor scores with mean of 0 and a standard deviation of 1 . Gender was coded 0 for women and 1 for men. Sample 2: $N=387$, except for organizational tenure $(N=374)$ 
Table 2

Results from the Latent Profile Analysis Models

\begin{tabular}{|c|c|c|c|c|c|c|c|c|c|c|}
\hline Model & $\mathrm{LL}$ & $\# f p$ & Scaling & AIC & CAIC & $\mathrm{BIC}$ & ABIC & Entropy & aLMR & BLRT \\
\hline \multicolumn{11}{|l|}{ Sample 1} \\
\hline 1 Profile & -712.471 & 6 & 0.915 & 1436.943 & 1462.265 & 1456.265 & 1437.261 & $\mathrm{Na}$ & $\mathrm{Na}$ & $\mathrm{Na}$ \\
\hline 2 Profiles & -644.111 & 10 & 1.069 & 1308.222 & 1350.426 & 1340.426 & 1308.753 & .827 & $<.001$ & $<.001$ \\
\hline 3 Profiles & -628.368 & 14 & 1.064 & 1284.735 & 1343.820 & 1329.820 & 1285.478 & .820 & .014 & $<.001$ \\
\hline 4 Profiles & -618.927 & 18 & 1.088 & 1273.853 & 1349.819 & 1331.819 & 1274.808 & .836 & .161 & $<.001$ \\
\hline 5 Profiles & -603.335 & 22 & 1.124 & 1250.670 & 1343.518 & 1321.518 & 1251.837 & .815 & .070 & $<.001$ \\
\hline 6 Profiles & -595.286 & 26 & 1.184 & 1245.572 & 1352.301 & 1326.301 & 1243.951 & .805 & .411 & .030 \\
\hline 7 Profiles & -586.679 & 30 & 1.180 & 1233.358 & 1359.968 & 1329.968 & 1234.949 & .837 & .363 & .030 \\
\hline 8 Profiles & -581.717 & 34 & 1.151 & 1231.433 & 1374.925 & 1340.925 & 1233.237 & .837 & .397 & .238 \\
\hline \multicolumn{11}{|l|}{ Sample 2} \\
\hline 1 Profile & -1650.536 & 6 & 0.903 & 3313.071 & 3342.822 & 3336.822 & 3317.784 & $\mathrm{Na}$ & $\mathrm{Na}$ & $\mathrm{Na}$ \\
\hline 2 Profiles & -1463.471 & 10 & 1.211 & 2946.942 & 2996.527 & 2986.527 & 2954.798 & .835 & $<.001$ & $<.001$ \\
\hline 3 Profiles & -1395.518 & 14 & 1.141 & 2819.037 & 2888.454 & 2874.454 & 2830.034 & .798 & $<.001$ & $<.001$ \\
\hline 4 Profiles & -1368.115 & 18 & 1.173 & 2772.229 & 2861.481 & 2843.481 & 2786.369 & .843 & .022 & $<.001$ \\
\hline 5 Profiles & -1349.943 & 22 & 1.169 & 2743.886 & 2852.971 & 2830.971 & 2761.167 & .838 & .145 & $<.001$ \\
\hline 6 Profiles & -1328.832 & 26 & 1.561 & 2709.663 & 2838.583 & 2812.583 & 2730.087 & .838 & .604 & $<.001$ \\
\hline 7 Profiles & -1316.279 & 30 & 1.204 & 2692.557 & 2841.310 & 2811.310 & 2716.123 & .845 & .035 & $<.001$ \\
\hline 8 Profiles & -1302.810 & 34 & 1.257 & 2673.620 & 2842.207 & 2808.207 & 2700.328 & .846 & .347 & $<.001$ \\
\hline \multicolumn{11}{|c|}{ Multiple-Group Models } \\
\hline Configural & -2313.309 & 45 & 1.143 & 4716.618 & 4957.330 & 4912.330 & 4769.474 & 0.882 & $\mathrm{Na}$ & $\mathrm{Na}$ \\
\hline Structural & -2336.489 & 30 & 1.192 & 4732.978 & 4893.452 & 4863.452 & 4768.215 & 0.866 & $\mathrm{Na}$ & $\mathrm{Na}$ \\
\hline Dispersion & -2339.111 & 27 & 1.291 & 4732.223 & 4876.649 & 4849.649 & 4763.936 & 0.865 & $\mathrm{Na}$ & $\mathrm{Na}$ \\
\hline Distributional & -2343.676 & 23 & 1.379 & 4733.352 & 4856.383 & 4833.383 & 4760.368 & 0.863 & $\mathrm{Na}$ & $\mathrm{Na}$ \\
\hline
\end{tabular}

Note. LL: model loglikelihood; \#fp: number of free parameters; scaling: scaling correction factor associated with robust maximum likelihood estimates; AIC: Akaïke information criteria; CAIC: constant AIC; BIC: Bayesian information criteria; ABIC: sample size adjusted BIC; aLMR: adjusted Lo-Mendel-Rubin likelihood ratio test; BLRT: bootstrap likelihood ratio test. 


\section{Table 3}

Associations between Profile Membership and the Outcomes

\begin{tabular}{|c|c|c|c|c|c|c|}
\hline & $\begin{array}{l}\text { Profile } 1 \\
\mathrm{M}[\mathrm{CI}]\end{array}$ & $\begin{array}{l}\text { Profile } 2 \\
\mathrm{M}[\mathrm{CI}]\end{array}$ & $\begin{array}{l}\text { Profile } 3 \\
\mathrm{M}[\mathrm{CI}]\end{array}$ & $\begin{array}{c}\text { Profile } 4 \\
\mathrm{M}[\mathrm{CI}]\end{array}$ & $\begin{array}{l}\text { Profile } 5 \\
\mathrm{M}[\mathrm{CI}]\end{array}$ & $\begin{array}{c}\text { Summary of Significant } \\
\text { Differences }\end{array}$ \\
\hline \multicolumn{7}{|l|}{ Sample 1} \\
\hline Emotional exhaustion $\uparrow$ & $\begin{array}{c}.014 \\
{[-.215 ; .243]}\end{array}$ & $\begin{array}{c}.909 \\
{[.531 ; 1.287]}\end{array}$ & $\begin{array}{c}.077 \\
{[-.423 ; .577]}\end{array}$ & $\begin{array}{c}-.070 \\
{[-.346 ; .206]}\end{array}$ & $\begin{array}{c}-.349 \\
{[-.580 ;-.118]}\end{array}$ & $\begin{array}{c}2>3=4=5 ; 2>1=3 ; \\
2>1=4 ; 1>5\end{array}$ \\
\hline Job satisfaction & $\begin{array}{c}3.065 \\
{[2.959 ; 3.171]}\end{array}$ & $\begin{array}{c}2.416 \\
{[2.161 ; 2.671]}\end{array}$ & $\begin{array}{c}2.672 \\
{[2.394 ; 2.950]}\end{array}$ & $\begin{array}{c}2.991 \\
{[2.848 ; 3.134]}\end{array}$ & $\begin{array}{c}3.443 \\
{[3.296 ; 3.590]}\end{array}$ & $5>1=4>2=3$ \\
\hline Absenteeism & $\begin{array}{c}2.591 \\
{[.862 ; 4.320]}\end{array}$ & $\begin{array}{c}23.614 \\
{[2.718 ; 44.510]}\end{array}$ & $\begin{array}{c}1.611 \\
{[-.516 ; 3.738]}\end{array}$ & $\begin{array}{c}2.952 \\
{[.361 ; 5.543]}\end{array}$ & $\begin{array}{c}6.911 \\
{[.735 ; 13.087]}\end{array}$ & $2>1=3=4$ \\
\hline Performance & $\begin{array}{c}7.013 \\
{[6.664 ; 7.362]}\end{array}$ & $\begin{array}{c}6.049 \\
{[5.240 ; 6.858]}\end{array}$ & $\begin{array}{c}6.913 \\
{[6.164 ; 7.662]} \\
\end{array}$ & $\begin{array}{c}6.788 \\
{[6.300 ; 7.276]}\end{array}$ & $\begin{array}{c}7.585 \\
{[7.273 ; 7.897]}\end{array}$ & $5>1>2 ; 5>4$ \\
\hline \multicolumn{7}{|l|}{ Sample 2} \\
\hline Affective commitment $\dagger$ & $\begin{array}{c}.099 \\
{[-.019 ; .217]}\end{array}$ & $\begin{array}{c}-1.039 \\
{[-1.180 ;-.898]}\end{array}$ & $\begin{array}{c}-.614 \\
{[-.981 ;-.247]}\end{array}$ & $\begin{array}{c}-.345 \\
{[-.498 ;-.192]}\end{array}$ & $\begin{array}{c}1.079 \\
{[.977 ; 1.181]}\end{array}$ & $5>1>3=4>2$ \\
\hline Job satisfaction $\dagger$ & $\begin{array}{c}.296 \\
{[.196 ; .396]}\end{array}$ & $\begin{array}{c}-1.254 \\
{[-1.411 ;-1.097]}\end{array}$ & $\begin{array}{c}-.704 \\
{[-1.149 ;-0.259]}\end{array}$ & $\begin{array}{c}-.430 \\
{[-.579 ;-.281]}\end{array}$ & $\begin{array}{c}1.083 \\
{[1.028 ; 1.138]}\end{array}$ & $5>1>3=4>2$ \\
\hline Absenteeism $\dagger$ & $\begin{array}{c}-.073 \\
{[-.165 ; .019]}\end{array}$ & $\begin{array}{c}.060 \\
{[-.277 ; .397]} \\
\end{array}$ & $\begin{array}{c}.161 \\
{[-.746 ; 1.068]}\end{array}$ & $\begin{array}{c}.040 \\
{[-0.197 ; .277]} \\
\end{array}$ & $\begin{array}{c}.017 \\
{[-.155 ; .189]}\end{array}$ & $5=4=2>3=1$ \\
\hline
\end{tabular}

Note. M: Mean; CI: 95\% confidence interval. $\uparrow$ Variables estimated from factor scores with mean of 0 and a standard deviation of 1. Profile 1: Moderately supported; Profile 2: Isolated; Profile 3: Supervisor supported; Profile 4: Weakly supported; Profile 5: Highly supported. 


\section{Online Supplements for: \\ A Person-Centered Perspective on Social Support in the Workplace}

\section{Authors' note:}

These online technical appendices are to be posted on the journal website and hot-linked to the manuscript. If the journal does not offer this possibility, these materials can alternatively be posted on one of our personal websites (we will adjust the in-text reference upon acceptance).

We would also be happy to have some of these materials brought back into the main manuscript, or included as published appendices if you deem it useful. We developed these materials to provide additional technical information and to keep the main manuscript from becoming needlessly long. 


\section{Preliminary Measurement Models}

For both samples, measurement models were estimated using Mplus 7.4 (Muthén \& Muthén, 2016) using the robust Maximum Likelihood (MLR) estimator, which provides parameter estimates, standard errors, and goodness-of-fit indices that are robust to the non-normality of the response scales used in the present study. These models were estimated in conjunction with Full Information Maximum Likelihood (FIML; Enders, 2010) procedures to account for the relatively limited amount of missing responses present at the item level (0\% in Sample 1; 0 to 3.36\% in Sample 2). Due to the complexity of the measurement models underlying all constructs assessed in this research and the fact that outcomes differed across samples, these analyses were conducted separately for the social support variables and the outcome measures involving multiple items (i.e., emotional exhaustion in Sample 1; affective commitment, job satisfaction, and absenteeism in Sample 2). This decision allowed us to assess the measurement invariances of the social support variables across samples.

\section{Perceived Support Models}

For Samples 1 and 2, a confirmatory factor analytic (CFA) model (e.g., Bollen, 1989) was used to represent the three a priori social support factors (perceived organizational support, perceived supervisor support, and perceived colleagues support) across both samples. An orthogonal method factor was included to control for the methodological artefact related to the negative wording of half of the items (Marsh, Scalas, \& Nagengast, 2010), and a priori correlated uniquenesses were included to account for the strictly parallel wording of the items forming the three subscales (Marsh et al., 2013; see also Stinglhamber \& Vandenberghe, 2004).

We also verified that this measurement model operated in the same manner across samples through tests of measurement invariance (Millsap, 2011): (1) configural invariance (which provides an indication of the adequacy of the CFA, with no added constraints), (2) weak invariance (loadings), (3) strong invariance (loadings and intercepts), (4) strict invariance (loadings, intercepts, and uniquenesses), (5) invariance of the latent variances-covariances (loadings, intercepts, uniquenesses, and latent variances-covariances), and (6) latent means invariance (loadings, intercepts, uniquenesses, latent variances-covariances, and latent means). We also incorporated an additional step between steps 4 and 5 to test the invariance of the a priori correlated uniquenesses. Given the known oversensitivity of the chi-square test of exact fit $\left(\chi^{2}\right)$ to sample size and minor model misspecifications (e.g., Marsh, Hau, \& Grayson, 2005), we relied on sample-size independent goodness-of-fit indices to describe the fit of the alternative models (Hu \& Bentler, 1999): the comparative fit index (CFI), the Tucker-Lewis index (TLI), as well as the root mean square error of approximation (RMSEA) and its 90\% confidence interval. Values greater than .90 for the CFI and TLI indicate adequate model fit, although values greater than .95 are preferable. Values smaller than .08 or .06 for the RMSEA respectively support acceptable and excellent model fit. Like the chi square, chi square difference tests present a known sensitivity to sample size and minor model misspecifications so that recent studies suggest complementing this information with changes in CFI and RMSEA (Chen, 2007; Cheung \& Rensvold, 2002) in the context of tests of measurement invariance. A $\triangle \mathrm{CFI} / \mathrm{TLI}$ of .010 or less and a $\triangle$ RMSEA of .015 or less between a more restricted model and the previous one supports the invariance hypothesis. Composite reliability coefficients associated with each of the a priori factors are calculated from the model standardized parameters using McDonald (1970) omega $(\omega)$ coefficient:

$$
\omega=\frac{\left(\sum\left|\lambda_{i}\right|\right)^{2}}{\left[\left(\sum\left|\lambda_{i}\right|\right)^{2}+\sum \delta_{i}\right]}
$$

where $\left|\lambda_{i}\right|$ are the standardized factor loadings associated with a factor in absolute values, and $\delta i$, the item uniquenesses. The numerator, were the factor loadings are summed, and then squared, reflects the proportion of the variance in in indicators that reflect true score variance, whereas the denominator reflects total amount of variance in the items including both true score variance and random measurement errors (reflects by the sum of the items uniquenesses associated with a factor).

The goodness-of-fit results for these models are reported in Table S1. These results support the adequacy of the a priori model (with most CFI/TLI $\geq .95$ and most RMSEA $\leq .08$ ). The results also support the configural, weak, and strong measurement invariance of this model across samples. However, the model of strict measurement invariance resulted in a decrease in goodness-of-fit indices which exceeded the recommended cut-off scores $(\Delta \mathrm{CFI} \leq .010 ; \Delta \mathrm{TLI} \leq .010 ; \Delta$ RMSEA $\leq .015)$, suggesting that the items uniquenesses were not fully invariant across samples. We thus pursued a 
model of partial strict invariance, in which the equality constraints across samples had to be relaxed on a total of 3 item uniquenesses (one per factor), showing that the level of random measurement error present in these items tended to be slightly larger in Sample 1, possibly due to the different modes of administration (paper in Sample 1 versus online in Sample 2). From this model of partial strict invariance, subsequent steps supported the invariance of the correlated uniquenesses, latent variances and covariances, and latent means. These results globally show that the parameter estimates obtained in Sample 2 can be considered to be roughly equivalent to those obtained in Sample 1. Thus, the parameter estimates and composite reliability scores obtained from the most invariant measurement model (latent mean invariance with partial strict invariance) are reported in Table S2. These results show that all factors are well-defined through satisfactory factor loadings $(\lambda=.682$ to .950$)$, resulting in satisfactory model-based composite reliability coefficients, ranging from $\omega=.900$ to .940 . Factor scores were saved from this most invariant model and used as profile indicators.

\section{Outcomes Models}

A similar procedure was followed to obtain factor scores for the multiple-item outcome measures used in both samples. For Sample 1, a single factor CFA model was used to reflect the emotional exhaustion construct. This model resulted in an acceptable level of fit to the data (e.g., CFI $=.956$; TLI $\geq .913)$, satisfactory estimates of all factor loadings $(\lambda=.563$ to .877$)$, and satisfactory estimates of composite reliability $(\omega=.889)$. In Sample 2, three distinct CFA factors were used to reflect the construct of affective commitment to the organization, job satisfaction, and absenteeism. An orthogonal method factor was included to control for the methodological artefact related to the negative wording of half of the items from the affective commitment scale (Marsh, Scalas, \& Nagengast, 2010). In addition, because the absenteeism factor was only defined by two items, essentially tau equivalent constraints were imposed on the unstandardized factor loadings associated with these items (they were constrained to equality) to help achieve the local identification of this factor and to locate it at the true centroid of the two indicators (Little, Lindenberger, \& Nesselroade, 1999). This model also resulted in an acceptable level of fit to the data (e.g., CFI $=.943$; TLI $=.920$ ), satisfactory estimates of all factor loadings $(\lambda=.637$ to .941$)$, and satisfactory estimates of composite reliability ( $\omega=.850$ to .930 ). Parameter estimates form these measurement models are reported in Table S3. The correlations between all variables (i.e., the factor scores and observed scores on single-item variables) are reported in the main manuscript.

\section{References used in this section of the supplements}

Bollen, K.A. (1989). Structural equations with latent variables. New York, NY: Wiley.

Chen, F.F. (2007). Sensitivity of goodness of fit indexes to lack of measurement. Structural Equation Modeling, 14, 464-504.

Cheung, G.W., \& Rensvold, R.B. (2002). Evaluating goodness-of fit indexes for testing measurement invariance. Structural Equation Modeling, 9, 233-255.

Enders, C.K. (2010). Applied missing data analysis. New York, NY: Guilford.

Hu, L.-T., \& Bentler, P.M. (1999). Cutoff criteria for fit indexes in covariance structure analysis: Conventional criteria versus new alternatives. Structural Equation Modeling, 6, 1-55.

Little, T.D., Lindenberger, U., \& Nesselroade, J.R. (1999). On selecting indicators for multivariate measurement and modeling with latent variables: When "good" indicators are bad and "bad" indicators are good. Psychological Methods, 4, 192-211.

Marsh, H.W., Abduljabbar, A.S., Abu-Hilal, M., Morin, A.J.S., Abdelfattah, F., Leung, K.C., Xu, M.K., Nagengast, B., \& Parker, P. (2013). Factor structure, discriminant and convergent validity of TIMSS math and science motivation measures: A comparison of USA and Saudi Arabia. Journal of Educational Psychology, 105, 108-128.

Marsh, H.W., Hau, K., \& Grayson, D. (2005). Goodness of fit in structural equation models. In A. Maydeu-Olivares \& J.J. McArdle (Eds.), Contemporary psychometrics: A festschrift for Roderick P. McDonald (pp. 275-340). Mahwah, NJ: Erlbaum.

Marsh, H.W., Scalas, L.F., \& Nagengast, B. (2010). Longitudinal tests of competing factor structures for the Rosenberg self-esteem scale: Traits, ephemeral artifacts, and stable response styles. Psychological Assessment, 22, 366-381.

McDonald, R. (1970). Theoretical foundations of principal factor analysis, canonical factor analysis, and alpha factor analysis. British Journal of Mathematical \& Statistical Psychology, 23, 1-21.

Millsap, R. (2011). Statistical approaches to measurement invariance. New York, NY: Taylor \& 
Online Supplements for Workplace Support Profiles S4

Francis.

Muthén, L.K., \& Muthén, B.O. (2015). Mplus user's guide. Los Angeles, CA: Muthén \& Muthén.

Stinglhamber, F., \& Vandenberghe, C. (2003) Organizations and supervisors as sources of support and targets of commitment. Journal of Organizational Behavior, 24, 251-270. 
Table S1

Goodness-of-Fit Statistics for the Estimated Models (Perceived Support)

\begin{tabular}{|c|c|c|c|c|c|c|c|c|c|c|}
\hline Description & $\chi^{2}(d f)$ & CFI & TLI & RMSEA & $90 \% \mathrm{CI}$ & $\mathrm{CM}$ & $\Delta \chi^{2}(d f)$ & $\Delta \mathrm{CFI}$ & $\Delta \mathrm{TLI}$ & $\triangle \mathrm{RMSEA}$ \\
\hline M1. Configural invariance & $146.979(66)^{*}$ & .978 & .956 & .065 & {$[.051 ; .080]$} & - & - & - & - & - \\
\hline M2. Weak invariance & $185.507(80)^{*}$ & .971 & .953 & .068 & {$[.055 ; .081]$} & M1 & $38.528(14)$ & -.007 & -.003 & +.003 \\
\hline M3. Strong invariance & $200.566(88)^{*}$ & .969 & .954 & .067 & {$[.055 ; .079]$} & M2 & $15.059(8)$ & -.002 & +.001 & -.001 \\
\hline M4. Strict invariance & $320.869(100)^{*}$ & .940 & .921 & .088 & {$[.077 ; .099]$} & M3 & $120.303(12)$ & -.029 & -.033 & +.021 \\
\hline M4'. Partial strict invariance & $219.384(97)^{*}$ & .967 & .955 & .066 & {$[.055 ; .078]$} & M3 & $18.818(9)$ & -.002 & +.001 & -.001 \\
\hline M5. Invariance of the CUs & $227.766(109)^{*}$ & .968 & .961 & .062 & {$[.050 ; .073]$} & M4' & $8.382(12)$ & +.001 & +.006 & -.004 \\
\hline M6. Var-Cov invariance & $245.447(116)^{*}$ & .965 & .960 & .062 & {$[.052 ; .073]$} & M5 & $17.681(7)$ & -.003 & -.001 & .000 \\
\hline M7. Latent means invariance & $266.946(120)^{*}$ & .960 & .956 & .065 & {$[.055 ; .076]$} & M6 & $21.499(4)$ & -.005 & -.004 & +.003 \\
\hline
\end{tabular}

Note. ${ }^{*} p<.05 ; \chi^{2}$ : scaled chi-square test of exact fit; $d f$ : degrees of freedom; CFI: comparative fit index; TLI: Tucker-Lewis index; RMSEA: root mean square error of

approximation; $90 \%$ CI: $90 \%$ confidence interval; CUs: correlated uniquenesses; Var-Cov: variance-covariance; CM: comparison model; $\Delta$ : change in fit relative to the CM. 
Table S2

Standardized Factor Loadings $(\lambda)$ and Uniquenesses $(\delta)$ for the $M 7$ solution (Latent Means Invariance with Partial Strict Invariance)

\begin{tabular}{|c|c|c|c|c|}
\hline Items & $\operatorname{OS} \lambda$ & $\operatorname{SS} \lambda$ & $\operatorname{CS} \lambda$ & $\delta$ \\
\hline \multicolumn{5}{|l|}{ Organizational Support } \\
\hline Item 1 & .910 & & & .172 \\
\hline Item 2 (Sample 1) & .684 & & & .451 \\
\hline Item 2 (Sample 2) & .801 & & & .245 \\
\hline Item 3 & .898 & & & .193 \\
\hline Item 4 & .682 & & & .056 \\
\hline$\omega($ Sample 1$)$ & .918 & & & \\
\hline$\omega($ Sample 2) & .940 & & & \\
\hline \multicolumn{5}{|l|}{ Supervisor Support } \\
\hline Item 1 (Sample 1) & & .856 & & .268 \\
\hline Item 1 (Sample 2) & & .950 & & .097 \\
\hline Item 2 & & .744 & & .340 \\
\hline Item 3 & & .883 & & .220 \\
\hline Item 4 & & .857 & & .105 \\
\hline$\omega($ Sample 1$)$ & & .923 & & \\
\hline$\omega$ (Sample 2) & & .939 & & \\
\hline \multicolumn{5}{|l|}{ Colleagues Support } \\
\hline Item 1 & & & .902 & .187 \\
\hline Item 2 & & & .724 & .399 \\
\hline Item 3 & & & .867 & .249 \\
\hline Item 4 (Sample 1) & & & .741 & .327 \\
\hline Item 4 (Sample 2) & & & .859 & .095 \\
\hline$\omega($ Sample 1) & & & .900 & \\
\hline$\omega($ Sample 2) & & & .924 & \\
\hline Factor Correlations & Organizational & Supervisor & Colleagues & \\
\hline \multicolumn{5}{|l|}{ Organizational } \\
\hline Supervisor & .735 & & & \\
\hline Colleagues & .356 & .377 & & \\
\hline
\end{tabular}

Note. $\lambda$ : factor loading; $\delta$ : item uniqueness; $\omega$ : omega coefficient of model-based composite reliability; OS = organizational support; $\mathrm{SS}=$ supervisor support; $\mathrm{CS}=$ colleagues support; $\mathrm{MF}=$ method factor; target factor loadings are indicated in bold. 
Table S3

Standardized Factor Loadings $(\lambda)$ and Uniquenesses $(\delta)$ for the Outcomes Measurement Models

\begin{tabular}{|c|c|c|c|c|c|}
\hline \multirow{2}{*}{ Items } & \multicolumn{5}{|c|}{ Factor 1.1 Factor 2.1 Factor 2.2 Factor 2.3} \\
\hline & $\lambda$ & $\lambda$ & $\lambda$ & $\lambda$ & $\delta$ \\
\hline \multicolumn{6}{|c|}{ 1.1.Emotional Exhaustion (Sample 1) } \\
\hline Item 1 & .831 & & & & .309 \\
\hline Item 2 & .748 & & & & .441 \\
\hline Item 3 & .877 & & & & .230 \\
\hline Item 4 & .866 & & & & .249 \\
\hline Item 5 & .563 & & & & .683 \\
\hline$\omega$ & .889 & & & & \\
\hline \multicolumn{6}{|c|}{ 2.1. Affective Commitment (Sample 2) } \\
\hline Item 1 & & .734 & & & .461 \\
\hline Item 2 & & .637 & & & .594 \\
\hline Item 3 & & .719 & & & .003 \\
\hline Item 4 & & .835 & & & .257 \\
\hline Item 5 & & .879 & & & .227 \\
\hline Item 6 & & .753 & & & .357 \\
\hline$\omega$ & & .916 & & & \\
\hline \multicolumn{6}{|l|}{ 2.2. Job Satisfaction (Sample 2) } \\
\hline Item 1 & & & .887 & & .214 \\
\hline Item 2 & & & .941 & & .115 \\
\hline Item 3 & & & .865 & & .252 \\
\hline Item 4 & & & .808 & & .347 \\
\hline$\omega$ & & & .930 & & \\
\hline \multicolumn{6}{|l|}{ 2.3. Absenteeism (Sample 2) } \\
\hline Item 1 & & & & .859 & .263 \\
\hline Item 2 & & & & .861 & .259 \\
\hline$\Omega$ & & & & .850 & \\
\hline Factor Correlations (Sample 2) & 2.1 & 2.2 & 2.3 & & \\
\hline \multicolumn{6}{|c|}{ 2.1. Affective Commitment (Sample 2) } \\
\hline 2.2. Job Satisfaction (Sample 2) & .723 & & & & \\
\hline 2.3. Absenteeism (Sample 2) & .070 & -.005 & & & \\
\hline
\end{tabular}

Note. $\lambda$ : factor loading; $\delta$ : item uniqueness; $\omega$ : omega coefficient of model-based composite reliability. 
Online Supplements for Workplace Support Profiles S8

Table S4

Detailed Parameter Estimates from the Final LPA Solution (Distributional Similarity)

\begin{tabular}{lcccccc}
\hline & Profile 1 & Profile 2 & Profile 3 & Profile 4 & Profile 5 & Variance \\
& Mean [CI] & Mean [CI] & Mean [CI] & Mean [CI] & Mean [CI] & {$[\mathrm{CI}]$} \\
\hline Organizational & .314 & -1.453 & -1.090 & -.541 & 1.070 & .192 \\
support & {$[.178 ; 450]$} & {$[-1.582 ;-1.325]$} & {$[-1.342 ;-.837]$} & {$[-.813 ;-.269]$} & {$[.913 ; 1.227]$} & {$[.090 ; .294]$} \\
Supervisor & .306 & -1.681 & .486 & -.659 & 1.023 & .148 \\
support & {$[.131 ; .481]$} & {$[-1.997 ;-1.365]$} & {$[.218 ; .755]$} & {$[-.841 ;-.476]$} & {$[.953 ; 1.094]$} & {$[.071 ; .224]$} \\
Colleagues & -.015 & -.492 & .106 & -.445 & .676 & .729 \\
support & {$[-.160 ; .131]$} & {$[-.799 ;-.185]$} & {$[-.410 ; .622]$} & {$[-.633 ;-.258]$} & {$[.534 ; .818]$} & {$[.642 ; .815]$} \\
\hline
\end{tabular}

Note. $\mathrm{CI}=95 \%$ confidence interval. The profile indicators are estimated from factor scores with mean of 0 and a standard deviation of 1. Profile 1: Moderately supported; Profile 2: Isolated; Profile 3:

Supervisor supported; Profile 4: Weakly supported; Profile 5: Highly supported. 
Table S5

Classification Accuracy: Average Probability of Membership into Each Latent Profile (Column) as a Function of the Most Likely Profile Membership (Row).

\begin{tabular}{lccccc}
\hline & Profile 1 & Profile 2 & Profile 3 & Profile 4 & Profile 5 \\
\hline Sample 1 & & & & & \\
Profile 1 & .856 & .000 & .014 & .055 & .076 \\
Profile 2 & .000 & .893 & .000 & .106 & .000 \\
Profile 3 & .037 & .000 & .921 & .042 & .000 \\
Profile 4 & .080 & .039 & .021 & .860 & .000 \\
Profile 5 & .146 & .000 & .000 & .000 & .854 \\
\hline Sample 2 & & & & & \\
Profile 1 & .839 & .000 & .025 & .051 & .084 \\
Profile 2 & .000 & .937 & .000 & .063 & .000 \\
Profile 3 & .108 & .000 & .832 & .052 & .009 \\
Profile 4 & .076 & .048 & .025 & .851 & .000 \\
Profile 5 & .096 & .000 & .000 & .000 & .904 \\
\hline Pre. PI
\end{tabular}

Note. Profile 1: Moderately supported; Profile 2: Isolated; Profile 3: Supervisor supported; Profile 4: Weakly supported; Profile 5: Highly supported. 


\section{Demographic Characteristics of the Social Support Profiles}

For purely descriptive purposes, we assessed the extent to which the identified social support profiles might be influenced by participants' demographic characteristics (age, organizational tenure, and sex). A strong assumption of LPA with covariates is that the nature of the profiles should remain unaffected by inclusion of the covariates (Diallo, Morin, \& Lu, 2017). To ensure that this did not happen, Morin, Meyer, Creusier, and Biétry (2016) recommend including predictors while using the start values from the retained unconditional LPA. Multinomial logistic regressions were conducted to test the relations between the demographic characteristics and profile membership. In these models, age and tenure were standardized to facilitate interpretations. Two alternative models were contrasted. First, relations between demographic characteristics and profile membership were freely estimated across samples $(\mathrm{AIC}=4621.496 ; \mathrm{CAIC}=4871.656 ; \mathrm{BIC}=4824.656 ;$ ABIC $=4675.456)$. Second, the predictive similarity of the model was tested by constraining predictions to equality across samples (AIC $=4609.623 ; \mathrm{CAIC}=4795.913 ; \mathrm{BIC}=4760.913 ; \mathrm{ABIC}=4649.806)$. This second model resulted in lower values for all information criteria and was thus retained, supporting the idea that relations between demographic characteristics and profile membership were equivalent across samples. Results from this model are reported in Table S6.

In line with the results from prior studies showing that age and tenure did not appear important in fostering perceived social support (Rhoades \& Eisenberger, 2002), our results revealed only limited associations between these characteristics and the likelihood of profile membership. Age was associated with a 1.5 times increased likelihood of membership into Profile 2 (isolated) relative to 1 (moderately supported), while tenure was associated with a 1.7 times increased likelihood of membership into Profile 5 (highly supported) relative to 3 (supervisor supported). In contrast, sex was more clearly associated with profile membership. Some of these associations could not even be computed given that Profile 3 (supervisor supported) was exclusively formed by women in Sample 2, and included 86\% of women in Sample 1, suggesting that women have a higher likelihood of membership into this profile relative to all others. Finally, women were more likely to be members of Profile 2 (isolated) relative to Profiles 1 (moderately supported), 4 (weakly supported), and 5 (highly supported). These findings suggest that women might still suffer from subtle forms of discrimination in the workplace, characterized by greater levels of social isolation (Baker, 2005). Fortunately, this does not seem to generalize to all supervisors given that employees who feel particularly well-supported by their supervisors relative to the organization and their colleagues are more likely to be women. An alternative explanation could be that women might be less prone to focus on social support within the workplace, and to attend to social events outside work, possibly due to a greater focus on the family. Future research needs to more extensively look at a broader set of theoretically-relevant predictors of profile membership (e.g., organizational justice; Kurtessis et al., 2017), and try to unpack the mechanisms underlying the relation between sex and sources of social support within, and outside of work settings.

\section{References used in this section of the supplements}

Baker, N.L. (2005). Women, work, and discrimination. In A. Barnes (Ed.), The handbook of women, psychology, and the law (pp.37-63). Hoboken, NJ: Wiley.

Diallo, T.M.O., Morin, A.J.S., \& Lu, H. (2017). The impact of total and partial inclusion or exclusion of active and inactive time invariant covariates in growth mixture models. Psychological Methods, 22, 166-190.

Kurtessis, J.N., Eisenberger, R., Ford, M.T., Buffardi, L. C., Stewart, K.A., \& Adis, C.S. (2017). Perceived organizational support a meta-analytic evaluation of organizational support theory, Journal of Management, 43, 1854-1884.

Morin, A.J.S., Meyer, J.P., Creusier, J., \& Biétry, F. (2016). Multiple-group analysis of similarity in latent profile solutions. Organizational Research Methods, 19, 231-254.

Rhoades, L., \& Eisenberger, R. (2002). Perceived organizational support: A review of the literature. Journal of Applied Psychology, 87, 698-714. 


\section{Table S6}

Results from Multinomial Logistic Regressions for the Effects of the Demographic Predictors on Profile Membership (Predictive Similarity)

\begin{tabular}{|c|c|c|c|c|c|c|c|c|c|c|}
\hline & \multicolumn{2}{|c|}{ Profile 1 vs. Profile 5} & \multicolumn{2}{|c|}{ Profile 2 vs. Profile 5} & \multicolumn{2}{|c|}{ Profile 3 vs. Profile 5} & \multicolumn{2}{|c|}{ Profile 4 vs. Profile 5} & \multicolumn{2}{|c|}{ Profile 1 vs. Profile 4} \\
\hline & Coef. (SE) & OR & Coef. (SE) & OR & Coef. (SE) & OR & Coef. (SE) & OR & Coef. (SE) & OR \\
\hline Sex & $.470(0.277)$ & 1.599 & $-.815(0.417)^{*}$ & .443 & $\mathrm{CNC}$ & $\mathrm{CNC}$ & $.371(.265)$ & 1.449 & $.099(.309)$ & 1.104 \\
\hline Age & $-.050(0.191)$ & .952 & $.351(0.191)$ & 1.420 & $.449(.309)$ & 1.567 & $.177(.157)$ & 1.194 & $-.227(.184)$ & .797 \\
\hline \multirow[t]{3}{*}{ Tenure } & $-.103(0.185)$ & .902 & $-.167(0.189)$ & .846 & $-.527(.267)^{*}$ & .590 & $-.015(.155)$ & .986 & $-.089(.191)$ & .915 \\
\hline & \multicolumn{2}{|c|}{ Profile 2 vs. Profile 4} & \multicolumn{2}{|c|}{ Profile 3 vs. Profile 4} & \multicolumn{2}{|c|}{ Profile 1 vs. Profile 3} & \multicolumn{2}{|c|}{ Profile 2 vs. Profile 3} & \multicolumn{2}{|c|}{ Profile 1 vs. Profile 2} \\
\hline & Coef. (SE) & OR & Coef. (SE) & OR & Coef. (SE) & OR & Coef. (SE) & OR & Coef. (SE) & OR \\
\hline Sex & $-1.185(0.426)^{* *}$ & .306 & $\mathrm{CNC}$ & $\mathrm{CNC}$ & $\mathrm{CNC}$ & $\mathrm{CNC}$ & $\mathrm{CNC}$ & $\mathrm{CNC}$ & $1.284(.440)^{* *}$ & 3.612 \\
\hline Age & $.174(0.193)$ & 1.190 & $.272(0.311)$ & 1.312 & $-.499(.331)$ & .607 & $-.098(.306)$ & .907 & $-.401(.204)^{*}$ & .670 \\
\hline Tenure & $-.152(0.206)$ & .859 & $-.512(0.275)$ & .599 & $.424(.279)$ & 1.528 & $.360(.279)$ & 1.434 & $.063(.211)$ & 1.066 \\
\hline
\end{tabular}

Note. $* p<.05$; ** $p<.01$; Gender was coded 0 for women and 1 for men.SE: Standard Error of the coefficient; OR: Odds Ratio. The coefficients and OR reflects the effects of the predictors on the likelihood of membership into the first listed profile relative to the second listed profile. CNC: coefficients could not be computed because Profile 3 includes only women; Profile 1: Moderately supported; Profile 2: Isolated; Profile 3: Supervisor supported; Profile 4: Weakly supported; Profile 5: Highly supported. 